\title{
Características y determinantes de la informalidad laboral en México
}

Enrique Cuevas Rodríguez, Hugo Antolín de la Torre Ruiz y Saúl Oswaldo Regala Dávila

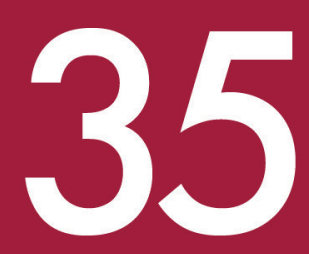

SEPTIEMBRE/ OCTUBRE 2016

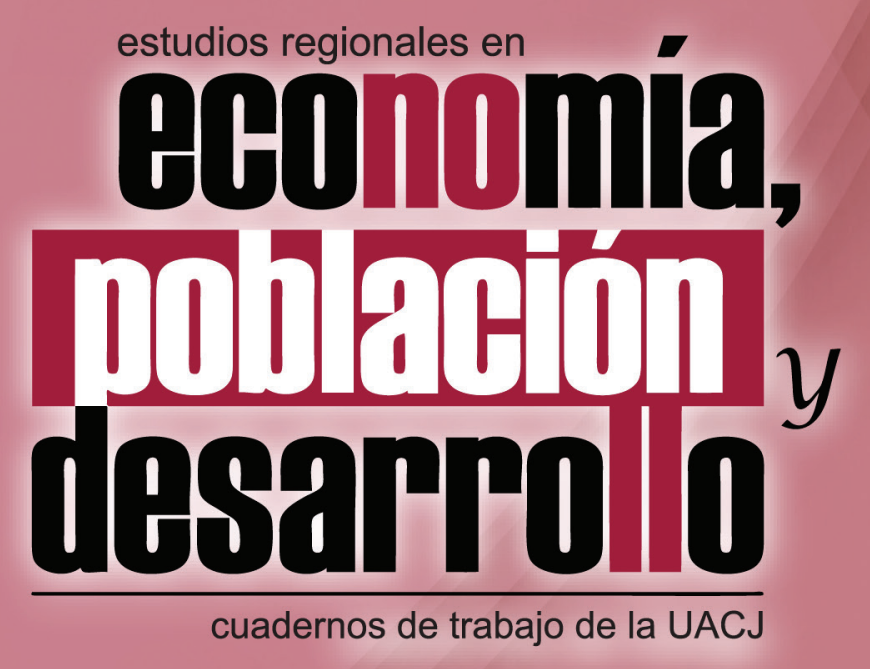




\title{
Características y determinantes de la informalidad laboral en México
}

\author{
Enrique Cuevas Rodríguez, Hugo Antolín de la Torre Ruiz y \\ Saúl Oswaldo Regla Dávila
}




\section{UNIVERSIDAD AUTÓNOMA DE CIUDAD JUÁREZ Instituto de Ciencias Sociales y Administración \\ Cuerpo Académico de Estudios Regionales en Economía, Población y Desarrollo}

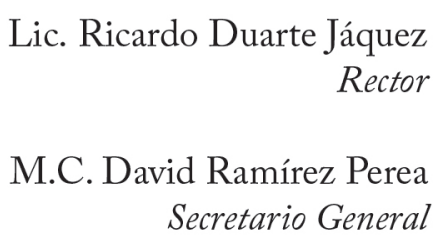

Mtro. Manuel Loera De la Rosa Secretario Académico

Mtro. Juan Ignacio Camargo Nassar Director del Instituto de Ciencias Sociales y Administración

Mtro. Ramón Chavira Chavira Director General de Difusión Cultura y Divulgación Cientifica

Dr. Luis Enrique Gutiérrez Casas Coordinador General de Investigación y Posgrado

Dr. Jaime Alberto Arellano Quiroga Coordinador del Cuerpo Académico de Estudios Regionales en Economia, Población y Desarrollo

Diseño de cubierta Alejandro Chairez

Abigail Bautista José Luis García

Universidad Autónoma de Ciudad Juárez Ave Plutarco Elías Calles 1210, Foviste Chamizal, C.P. 32310 Ciudad Juárez, Chihuahua, México www.uacj.mx

(C) Universidad Autónoma de Ciudad Juárez

\section{Comité editorial:}

Dra. Myrna Limas Hernández

Mtro. Wilebaldo Lorenzo Martínez Toyes

Dr. Raúl Ponce Rodríguez

Dr. Isaac Leobardo Sánchez Juárez

Mtra. María Del Socorro Velázquez Vargas

Dr. Luis Enrique Gutiérrez Casas

Editor y Coordinador de Cuadernos de Trabajo

Estudios Regionales en Economía, Población

y Desarrollo. Cuadernos de Trabajo de la UACJ

ISSN 2007-3739

Número 35. Septiembre/ Octubre 2016

Características y determinantes de la

informalidad laboral en México

Enrique Cuevas Rodríguez, Hugo Antolín de la Torre Ruiz y

Saúl Oswaldo Regla Dávila

$$
\text { Universidad Autónoma de Ciudad Juárez }
$$

Estudios Regionales en Economía, Población y Desarrollo. Cuadernos de Trabajo de la UACJ

Año 6, No. 35 septiembre - octubre 2016, es una publicación bimestral editada por la Universidad Autónoma de Ciudad Juárez a través del Cuerpo Académico de Estudios Regionales en Economía, Población y Desarrollo del Instituto de Ciencias Sociales y Administración. Redacción: Avenida Universidad y H. Colegio Militar, Zona Chamizal s/n., C.P. 32300, Ciudad Juárez, Chihuahua, México. Teléfonos: (656) 688-38-00, ext. 3792. Correo electrónico: 1gtz@uacj.mx.

Editor responsable: Luis Enrique Gutiérrez Casas. Reserva de derechos al uso exclusivo No. 04-2011-021713353900-102. ISSN 2007-3739, Impresa por Studio Los Dorados, calle Del Campanario, número 820-2, Santa Cecilia, C.P. 32350, Cd. Juárez, Chihuahua. Distribuidor: Subdirección de Gestión de Proyecto y Marketing Editorial. Ave. Plutarco Elías Calles 1210, Foviste Chamizal, C.P. 32310, Ciudad Juárez, Chihuahua. Este número se terminó de imprimir el 15 de agosto 2016 con un tiraje de 120 ejemplares.

Los ensayos publicados son responsabilidad exclusiva de sus autores. Se autoriza la reproducción total o parcial bajo condición de citar la fuente.

\section{Registrada en: EBSCO REPEC}

Publicación afiliada a la Red Iberoamericana de Estudios del Desarrollo 
Estudios Regionales en Economía, Población y Desarrollo. Cuadernos de Trabajo de la UACJ, Universidad

Autónoma de Ciudad Juárez, número 35, septiembre-octubre de 2016, ISSN 2007-3739, pp. 3-26, México.

\title{
Características y determinantes de la informalidad laboral en México
}

\author{
Enrique Cuevas Rodríguez*, Hugo Antolín de la Torre Ruiz** y \\ Saúl Oswaldo Regla Dávila***
}

\begin{abstract}
Resumen
Desde el año 2012 el Instituto Nacional de Estadística y Geografía de México (INEGI), adoptó el enfoque de informalidad laboral y lo integró a mediciones realizadas con información captada por la Encuesta Nacional de Ocupación y Empleo (ENOE). En este documento se estudian las características individuales de los trabajadores informales bajo el enfoque de informalidad laboral citado. Entre estas características se incluyeron el género (sexo) del trabajador, edad, escolaridad y ubicación geográfica según nivel de marginación de la entidad federativa en donde labora. Se encontró que la informalidad laboral está asociada a condiciones de alta vulnerabilidad o precarización socio demográfica del trabajador, tales como: baja o nula escolaridad, alta marginación, mujeres en general, sobre todo aquellas con hijos pequeños, jóvenes en general y su extremo, los mayores de 65 años. Se mostró además que la informalidad laboral funge como mecanismo para mantener bajas las tasas de desocupación, por lo que se presenta una especie de trade-off -sobre todo en épocas de crisis- entre esas dos alternativas de participación. Se utilizaron métodos econométricos (análisis probit) con microdatos de la ENOE de 2015.
\end{abstract}

Palabras clave: informalidad laboral, trabajador informal, tasa de desocupación, México.

\begin{abstract}
Since 2012 the National Institute of Statistics and Geography of Mexico (INEGI), adopted the approach of labor informality and integrated it to measurements made with information collected by the National Survey of Occupation and Employment (ENOE). Under the aforementioned approach, in this paper the individual characteristics of informal workers are studied. Thus, they were included gender, age, education, and geographic location according at marginalization level by federal entity where he works. It was found that labor informality is associated with high vulnerability conditions or socio-demographic insecurity, such as low or no education, high poverty, women with young children, young people in general and workers over 65 years. It also showed that labor informality serves as a mechanism to maintain low the unemployment rates, so a kind of trade-off occurs especially in times of crisis between these two alternatives. Econometric methods (probit analysis) were used with the ENOE 2015 microdata.
\end{abstract}

Key words: Informal economy, labor informality, unemployment rate, Mexico.

JEL Classification: J10, J46, J18.

- Recibido en: Junio de 2016

- Aprobado en: Agosto de 2016

\footnotetext{
* Investigador adscrito al Departamento de Métodos Cuantitativos del Centro Universitario de Ciencias Económico Administrativas (CUCEA) de la Universidad de Guadalajara. Responsable del proyecto: Observatorio Social y Laboral del CUCEA. Correo electrónico: ecuevas@cucea.udg.mx.

** Becario adscrito al proyecto: Observatorio Social y Laboral del CUCEA.

*** Colaborador en la investigación sobre informalidad laboral en México a través del Observatorio Social y Laboral del CUCEA.
} 


\section{$\rightarrow$ 1. Introduction. ${ }^{1}$}

La capacidad de la economía mexicana para generar empleos formales es muy limitada, ya que casi dos terceras partes de la población ocupada, el 60\%, es informal. Las consecuencias de ello sobre la economía y los trabajadores en general son diversas, pero todas tienen un eje común: precarización del empleo y sus efectos en la pérdida del bienestar de los trabajadores, lo que a su vez impacta en la reducción de la demanda agregada total, e impone algunas restricciones al crecimiento económico.

El concepto de trabajador informal que se adopta en este documento, es el dado a conocer por el Instituto Nacional de Estadística y Geografía (INEGI) de México desde el año 2012, con recomendaciones de la Organización Internacional del Trabajo (OIT). El concepto comprende no sólo a los trabajadores que laboran en unidades económicas informales, sino también a todos aquellos que, aun laborando en el sector formal, no pueden hacer efectivos ciertos derechos (seguridad social, beneficios no salariales, liquidación o finiquito al término de la relación de trabajo) ni tener acceso a las instituciones de salud, y se sumó también a los ocupados en la agricultura de auto subsistencia (OIT, 2014, pp. 3-7).

La economía informal se mantiene por los beneficios de omitir pagos y obligaciones con las dependencias de gobierno, pero también, por el complejo proceso para convertirse en formal. De acuerdo a Ricardo Rodarte (2003, p. 27), en México la economía no ofrece los empleos necesarios para cubrir la demanda de empleo formal, el cual tenga remuneraciones y esté protegido adecuadamente por la legislación laboral. Sin embargo, aunque la actividad informal se desempeña en diferentes entornos y con distintas condiciones, generalmente implica malas condiciones laborales, además está relacionado con el incremento de la pobreza (OIT, 2014, p. 7). Todo ello da cuenta de que la informalidad laboral se asocia a la existencia de inequidades en los mercados de trabajo, y presiona a un gran número de trabajadores ocupados a optar por la informalidad laboral, precisamente por sus condiciones de vulnerabilidad y desventaja.

El objetivo del presente trabajo es doble. Por una parte se analizarán algunas de las características de la informalidad laboral, su concepto, medición, relación con el desempleo y con la pobreza. En segundo lugar se estimarán los determinantes de la probabilidad de la población ocupada para trabajar como informales. Se consideran las características individuales de los ocupados, tales como el género (sexo), edad, escolaridad y ubicación geográfica según nivel de marginación de la entidad federativa en donde laboran. En el caso de las estimaciones realizadas para las mujeres, se consideró el tener o no hijos.

1 Los autores agradecen las sugerencias y correcciones realizadas por el Dr. José Héctor Cortés Fregoso, así como de Claudia Patricia Mendoza Ramírez, egresada de la Licenciatura en Economía del Centro Universitario de Ciencias Económico Administrativas (CUCEA) de la Universidad de Guadalajara (UdeG) y colaboradora en el proyecto: Observatorio Social y Laboral adscrito al Departamento de Métodos Cuantitativos de esa misma institución. 
La relación entre desempleo e informalidad es preocupante debido a la existencia de evidencias que muestran una relación inversa entre esas dos condiciones de participación laboral, derivada de la incapacidad de la economía formal para absorber la gran cantidad y cada vez creciente mano de obra que se incorpora a la Población Económicamente Activa (PEA).

El trabajo se realizó con datos del INEGI ${ }^{2}$ provenientes de la Encuesta Nacional de Ocupación y Empleo (ENOE) a nivel de registro. Se utilizaron los datos que corresponden al segundo trimestre de 2015, por ser éste el que el INEGI considera representativo del año en cuestión debido a la relativa estabilidad del empleo y las condiciones de ocupación en relación al resto del año.

Se utiliza la técnica del análisis de regresión probit, porque es un instrumento adecuado para hacer estimaciones de funciones de probabilidad, y que también es utilizado de manera muy común en el análisis de fenómenos laborales.

El artículo se divide en tres apartados, en el primero se revisa el marco teórico y conceptual que contribuye a explicar el fenómeno de la informalidad laboral y a justificar las variables que se incluyeron en esta investigación. En la segunda parte se analizan se hace un análisis descriptivo de los datos que constituyeron la base de información relevante para la realización del documento. En la tercer parte se obtienen los determinantes de la probabilidad de los ocupados de participar como informales en el mercado de trabajo. Por último se presentan las conclusiones.

\section{$\rightarrow$ 2. Algunas explicaciones del surgimiento y causas del empleo informal y la precarización de la mano de obra.}

Por sus características el empleo informal está directamente asociado a empleos precarios que repercuten negativamente en el nivel de vida y condiciones laborales del trabajador ocupado, debido a que se trata de personas que carecen de prestaciones laborales, seguridad y/o estabilidad en el trabajo, así como de ingresos salariales relativamente bajos, de ahí la afirmación de Tokman, de que "en la actualidad, los informales no pueden cumplir con los requisitos y costos que implica la incorporación a la formalidad" (Tokman, V. E., 2001, p. 20).

El concepto de precariedad laboral abarca tres dimensiones. El primero hace referencia a la inestabilidad e inseguridad del empleo, el cual es originado en la prevalencia de contratos flexibles y temporales, lo cual no solo aumenta el riesgo de caer en desempleo, sino además, deja a los trabajadores sin protección social (Antón, 2006).

La segunda dimensión hace referencia a las condiciones laborales internas, a la inseguridad y riesgos para la salud laboral de las condiciones de trabajo, a una excesiva movilidad geográfica, junto con la flexibilidad de horarios y la prolongación de la jornada de trabajo (horas extras).

2 Un listado de las abreviaturas utilizadas en este documento se presenta al final, en el anexo 2. 
Unos salarios muy bajos son un indicador significativo de esas condiciones laborales de precariedad (Antón, 2006).

La tercera dimensión hace alusión a la situación de mayor indefensión y vulnerabilidad de esos sectores precarios en las empresas. Una vertiente es la existencia de menor protección social, menores garantías y derechos de los trabajadores, pero la expresión más notable es esa situación de fragilidad y subordinación del poder empresarial y las dinámicas de exigencia por parte de las empresas. En suma se busca un debilitamiento del poder contractual de trabajadores y sindicatos.

Las tres dimensiones están relacionadas: un empleo precario, o inseguridad en el empleo, suele ir acompañado de salarios bajos, mayor indefensión y subordinación empresarial.

Antonio Antón expone la precariedad en términos generales, es decir, no se centra en el sector informal, sino que abarca tanto la informalidad como la formalidad. Él menciona que hay solo dos indicadores fundamentales para definir la precariedad laboral, tipo de contrato temporal y paro de labores, pero son insuficientes, puesto que, por un lado, los nuevos contratos indefinidos también reflejan una inestabilidad similar a la de muchos contratos temporales y se puede asociar a la precariedad laboral.

En México se tiene la dimensión de precariedad laboral asociada en gran parte del mercado de trabajo secundario y a los mercados laborales externos. La precariedad laboral -incorporando el desempleo y el trabajo irregular- se diferencia del empleo de "calidad". Incluye otros conceptos como: inestable, inseguro, temporal, discriminatorio o injusto y con pocos derechos. Todos ellos tienen su contrario: estable, seguro, fijo, digno, con plenos derechos y garantías. Igualmente, frente al polo de la irregularidad o ilegalidad y la arbitrariedad empresarial, existe el de condiciones laborales reguladas. Todo ello es consistente con la afirmación de Tokman: "en países de menor desarrollo relativo, el problema de empleo se concentra no tanto en el desempleo sino, principalmente, en aquellos que estando ocupados reciben un ingreso insuficiente" (Tokman, V. E., 2001, p. 12).

Para la Comisión Económica para América Latina (CEPAL), el sector informal constituye una suerte de refugio o estrategia de subsistencia para los grupos marginados, que contribuye no sólo a generar, sino también a reforzar, la exclusión y las tensiones sociales. Así, desde el punto de vista macroeconómico, el sector informal dificulta el crecimiento económico y aumenta las disparidades de salarios. Por lo tanto, los estructuralistas, como alternativa a las políticas de flexibilización y legalización ortodoxas, son partidarios de aplicar políticas industriales y de producción ajustadas a la realidad, que fomenten el cambio estructural y la absorción de mano de obra por el sector formal para acelerar el crecimiento de la economía (CEPAL, 2006, p. 91).

Una visión internacional sobre el acelerado crecimiento del empleo informal lo señala Pedrero (2009, p. 119), de acuerdo a esta autora el surgimiento de una interdependencia económica internacional y de interacción a distancia que se ha venido incrementado desde 1960, ha provocado el do- 
minio del capital sobre el trabajo, surgiendo una división internacional del trabajo dejando grandes volúmenes importantes de trabajadores que no son absorbidos por las empresas.

Las actividades productivas que se han desarrollado con alta tecnología en capital y las grandes transacciones comerciales se generan en oligopolios que establecen fuertes matrices comerciales gracias a las políticas neoliberales, en muchas de las ocasiones -y en contraste- los centros de distribución son ocultos, llegan al consumidor a través de vendedores ambulantes (comercio informal). En consecuencia, se tiene un deterioro en el trabajo asalariado, además de la reducción de oportunidades del propio empleo formal, orillando a buscar nuevas oportunidades que por lo regular son encontradas en la actividad informal. Ante esta polarización de la economía se ha incrementado la precarización entre los trabajadores (Pedrero-Nieto, 2009, p. 120).

En México una gran parte del $60 \%$ de la población que aporta su actividad laboral al sector informal, se encuentra en trabajos precarios, de bajos ingresos y sin acceso a la seguridad social, provocando una gran dispersión de los ingresos y de los propios salarios. Ante esto, no se cuenta con un efecto significativo en la tasa de desempleo porque la población que pierde su empleo recurre al autoempleo (comercio ambulante y prestación de servicios), de ahí que la tasa de desocupación se mantenga relativamente baja, de entre el 4.5 y 5.5 por ciento en los últimos diez años.

Con la ausencia de mecanismos regulatorios como un seguro de desempleo y la falta de buenas remuneraciones no existe la oportunidad de contar con un fondo de ahorro para tener la posibilidad de buscar un empleo nuevo sin la necesidad de recurrir al empleo informal (Ruesga \& Fujii, 2006, p. 17).

De acuerdo a Perry (2008, p. 247) el empleo informal ha ido en aumento por las exclusiones de los beneficios básicos, ya sea por parte del Estado o de los circuitos de la economía moderna. El autor plantea tres posibles panoramas que provocan las exclusiones entre la formalidad y la informalidad.

En primer lugar, la segmentación laboral que ha tomado lugar los últimos años impide que los trabajadores ocupados en el sector informal dejen su actividad para desempeñarse en un empleo formal que les ofrezca beneficios estipulados por las leyes. En segundo lugar, la dificultad de cumplir las reglas para pasar de la informalidad a la formalidad provoca que no crucen la frontera las empresas pequeñas sin oportunidad de prosperar. En tercer lugar, las grandes empresas se ven orilladas a la operación de la informalidad como defensa a este fenómeno, sin embargo, debilita el sector fiscal por la evasión de impuestos (Perry, 2008, p. 13).

La informalidad no solo tiene efectos desfavorables en el desempeñode la economía en términos de precariedad laboral, marginación y disparidades de ingresos, sino que además afecta directamente a la productividad agregada y por consecuencia al crecimiento económico, reduciendo así la productividad económica, puesto que, las actividades informales son de bajo rendimiento 
y la concentración de la fuerza de trabajo en el sector menos eficiente hace caer la productividad agregada, generando un "atascamiento" en el crecimiento económico (CEPAL, 2006, p. 94).

El problema de la precarización y, en cierta forma, de la existencia de la informalidad laboral, es congruente con los planteamientos de Arthur Lewis (1979, pp. 139-191) quien, desde 1950, explicaba en su modelo de sectores duales, que el sector tradicional de la economía estaba conformado por un gran excedente de mano de obra y bajos salarios en los países en desarrollo, y que éste "problema" se absorbería gradualmente en el sector industrial moderno a medida que esas economías crecieran, además no estaba vinculado con la economía formal ni con el desarrollo capitalista moderno (Rodgers, 2002, p. 11).

En la década de los setenta, como resultado de varias investigaciones sobre el mercado laboral urbano en Ghana realizadas por el antropólogo económico Keith Hart, hizo una de las primeras menciones del término "informalidad", señalando que la formalidad equivale a un empleo remunerado y la informalidad significa un trabajo por cuenta propia (Hart, 1973, p. 68).

El término se expandió después de que la Organización Internacional del Trabajo (OIT) lo utilizará en un análisis que realizaron sobre el empleo en Kenia, observando que en dicho sector no se llevaba a cabo ningún registro ni regulación (Rodgers, 2002, p. 67).

Para las siguientes décadas se desarrollaron diversos debates sobre la esencia y causas de la informalidad:

a) Escuela de pensamiento legalista, defendida por Hernando de Soto Polar, quien mencionaba que el sector informal estaba conformado por microempresarios que intentaban evitar obligaciones fiscales que llevaran a la quiebra sus empresas.

b) Escuela dualista afirmaba que la informalidad se debía a un desequilibrio que se daba cuando la oferta de trabajo crecía más rápido que el desarrollo económico.

c) Escuela estructuralista, respaldada principalmente por Alejandro Portes mencionaba que el sector informal era una característica del desarrollo capitalista.

d) Escuela ilegalista sostenía que la informalidad era una manera de que las empresas evitaran pagar impuestos y tener más ganancias (Rodgers, 2002, p. 69).

Luego el término "economía informal" se acuña en el año 2002 por la Conferencia Internacional del Trabajo, porque pasó a ser un tema de interés para los países en vías de desarrollo así como para los países en desarrollo, por ser ya un fenómeno económico donde se asegura que la informalidad permanece y se expande.

Se consideró que la economía informal era una "modalidad urbana" caracterizada por: 1) la exigüidad de los obstáculos al ingreso, en lo que se refiere a las aptitudes, el capital y la organización; 2) la propiedad familiar de las empresas; 3) lo reducido de la escala de operaciones; 4) el empleo de métodos de producción de gran densidad de mano de obra y de tecnologías anticuadas; y 5) la 
existencia de mercados no regulados y competitivos (Klein \& Tokman, 1988; Sethuraman, 1981). Posteriormente el Programa Regional del Empleo para América Latina y el Caribe (PREALC) de la OIT, publicó que el empleo en el sector informal se denominó sistemáticamente "subempleo" y se supuso que quienes participaban en él no lograban ingresar a la economía moderna (Klein \& Tokman, 1988).

\section{$\Rightarrow$ 3. Los datos sobre la informalidad en México. ${ }^{3}$}

Antes de presentar y analizar los datos del INEGI, es conveniente precisar el concepto que la estadística oficial mexicana utiliza. Primeramente debe señalarse que, hasta el año 2012, el INEGI definía la informalidad desde un enfoque de sector informal. Este enfoque "se centra en las características de las unidades económicas no agropecuarias que no se constituyen como empresas y que no cumplen con los registros más básicos que la legislación demanda de proveedores de bienes y servicios. El ambulantaje es un caso paradigmático al respecto" (INEGI, 2014; p. III). Pero a partir de 2012, con base en las recomendaciones de la OIT, derivadas particularmente de la Decimoséptima Conferencia Internacional de Estadísticos del Trabajo (CIET), llevada a cabo desde 2003, incorporó el concepto de informalidad laboral, en el cual se incluyó, además de los considerados en el sector informal (definición previa a 2012), el llamado enfoque de condiciones laborales, el cual aplica a los trabajadores subordinados remunerados (asalariados, por comisión, y/u honorarios) así como a los trabajadores familiares que participan en la actividad sin tener un acuerdo de remuneración monetaria. "Los trabajadores bajo esta situación pueden estar recibiendo un salario o manejando la relación laboral como si fuera mercantil (trabajadores por comisión u honorarios) pero el hecho es que, como también sucede en el servicio doméstico, no pueden hacer efectivos ciertos derechos laborales (seguridad social, beneficios no salariales, liquidación o finiquito al término de la relación de trabajo) ni tener acceso a las instituciones de salud comprendidas dentro de esos derechos. Estos casos no caen dentro del ámbito del sector informal, porque la empresa o institución para las que aportan sus servicios están perfectamente constituidas como tales o, como mínimo, el negocio ya está registrado ante la autoridad fiscal." (INEGI, 2014; pp. 5-6).

Durante el período que va de 2005 a 2015, el porcentaje de personas ocupadas en condición de informalidad, se ha mantenido en promedio en alrededor del 60\% (58.8\%), esto es, que aproximadamente 6 de cada 10 personas ocupadas trabajan en el sector informal, esta es la llamada tasa de informalidad laboral o TIL, por su abreviación, la cual se incrementa significativamente en los

3 El estudio y análisis del documento se llevó a cabo con información captada, a nivel de registro, por la Encuesta Nacional de Ocupación y Empleo (ENOE), que trimestralmente aplica el INEGI en todo el territorio nacional y que tiene una representatividad no sólo a nivel de todo el país, sino también por entidad federativa.

Economía, Población y Desarrollo. Cuadernos de Trabajo de la UACJ, núm. 35, sep-oct 2016 
períodos de crisis, tales como 2008-2011 (ver gráfica 1). En términos absolutos, la PEA en México se conforma de 48.7 millones de personas (promedio entre 2005 y 2015) y de éstos, 46.5 millones son ocupados. La magnitud del trabajo informal promedio en ese período es de 27.3 millones de personas. Entre esos 10 años, el tamaño de la informalidad laboral pasó de 24.5 millones en 2005 a 29.6 millones de personas en $2015 .{ }^{4}$

\subsection{Las características de la informalidad laboral.}

Tal y como se mencionó en la introducción y la sección previa de este trabajo, el sector informal está asociado a la precarización del empleo. Para dar cuenta de ello se presentan, en la tabla 1, algunos indicadores sobre prestaciones sociales, ingresos y horas de trabajo.

Si se toman al total de ocupados "con seguridad social" de los datos de la ENOE de 2015, el 99.97\% son formales inscritos a algún régimen de esta seguridad, lo cual garantiza servicios se salud públicos y pertenecen a un régimen de pensiones y jubilaciones. El restante $0.03 \%$ corresponde a los ocupados informales.

Por otra parte, tomando los datos del total de ocupados que en la ENOE manifestaron no tener seguridad social, sólo el $8.62 \%$ son formales, mientras que el restante $91.38 \%$ informales. Ese porcentaje de formales sin seguridad social, básicamente representa a un cierto grupo de trabajadores temporales y/o quienes rechazan la filiación al seguro social con la finalidad de que no se les descuente de su nómina corriente.

\section{Gráfica 1}

\section{MÉXICO: Tasa de infortalidad laboral, 2005-2015}

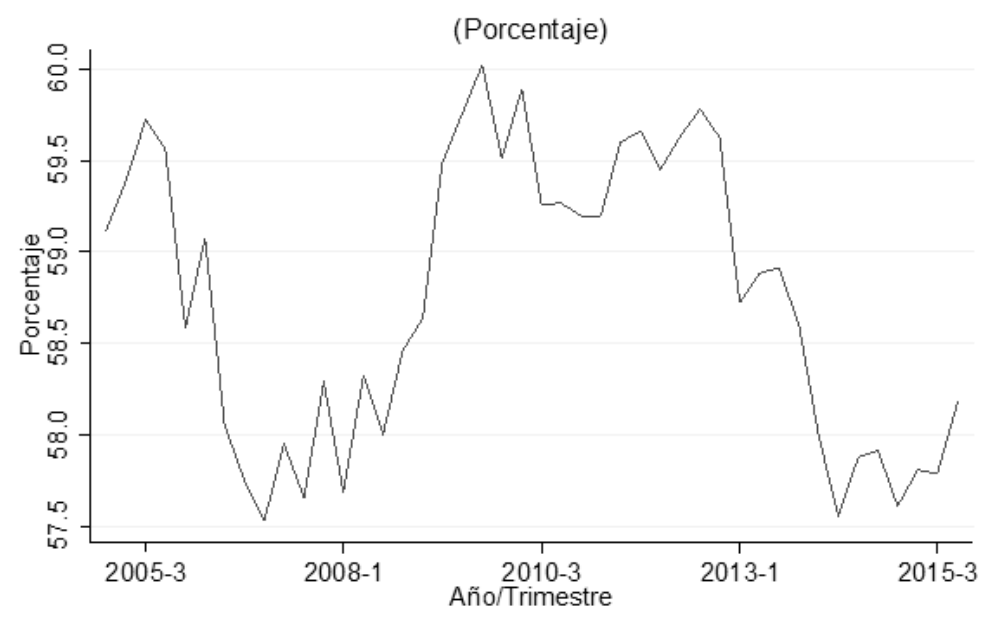

Fuente: Elaboración propia con datos de ENOE (STPS, 2016).

4 Se tomaron los datos de los segundos trimestres de cada año por ser éstos los más estables, y por lo tanto representativos del año según el INEGI. 
E1 88\% de los informales no cuenta con ningún tipo de prestación, tan solo el $0.02 \%$ tiene acceso a instituciones de salud, en cambio, el 11.19\% no tiene prestación en materia de salud pero si a otras prestaciones. Por último el $1.42 \%$ restante no especificó.

En contra parte, el $82.96 \%$ del sector formal cuenta con acceso a instituciones de salud, y a su vez a otras prestaciones; el 4.30\% restante sólo cuenta con prestaciones en materia de salud. Esto puede ser porque, cuando hay contratos temporales los trabajadores que se convierten en formales por un tiempo determinado tienen derecho por ley a una prestación de salud, sin embargo las empresas no tienen la obligación de otorgarles otras prestaciones, o bien, simplemente las evaden. E1 12.7\% de los formales no cuentan con ninguna prestación.

El ingreso es un indicador muy importante para observar el nivel de precarización laboral. El ingreso promedio mensual de un trabajador informal es de $\$ 3,783.42$ mientras que para el trabajador formal es de $\$ 7,394.50$, es decir, la proporción del salario mensual de los informales con respecto a los formales, es del 51.2 por ciento.

Las horas de trabajo muestran que el trabajador formal en promedio tiende a trabajar más porque tiene horas fijas establecidas por la legislación laboral, en cambio el informal en promedio trabaja menos, puesto que no tiene un horario obligatorio o quizás porque se trate de empleos temporales. Los resultados se observan en la tabla antes mencionada donde se expone que las horas de trabajo promedio para un formal son de 45 horas y para el informal de 38 horas.

Cuadro 1

MÉXICO: Características del empleo formal e informal, 2015.

\begin{tabular}{|c|c|c|}
\hline Indicador & Formal & Informal \\
\hline Acceso a la seguridad social & \multicolumn{2}{|c|}{ Porcentajes } \\
\hline Con seguridad social & $99.97 \%$ & $0.03 \%$ \\
\hline Sin seguridad social & $8.62 \%$ & $91.38 \%$ \\
\hline \multicolumn{3}{|l|}{$\begin{array}{l}\text { Prestaciones diversas (\% respecto al total de } \\
\text { formales e informales) }\end{array}$} \\
\hline Sin prestaciones & $12.70 \%$ & $88.03 \%$ \\
\hline Solo acceso a instituciones de salud & $4.30 \%$ & $0.02 \%$ \\
\hline Acceso de instituciones de salud y otras prestaciones & $82.96 \%$ & $0.00 \%$ \\
\hline $\begin{array}{l}\text { Sin prestaciones a instituciones de salud pero si a } \\
\text { otras prestaciones }\end{array}$ & $0.00 \%$ & $11.19 \%$ \\
\hline No especificado & $0.04 \%$ & $0.76 \%$ \\
\hline Total & $100.0 \%$ & $100.0 \%$ \\
\hline \multicolumn{3}{|l|}{ Ingresos y horas trabajadas } \\
\hline & \multicolumn{2}{|c|}{ Promedios } \\
\hline Ingreso mensual & $\$ 7,394.50$ & $\$ 3,783.42$ \\
\hline Horas de trabajo semanal & 44.99 & 38.36 \\
\hline
\end{tabular}

Fuente: Elaboración propia con datos de ENOE, 2015. 


\subsection{Distribución espacial de la informalidad en México.}

Para observar otra de las características de la informalidad, y determinar si existe algún patrón de comportamiento según alguna particularidad de las entidades federativas de México, se muestra el mapa 1. Se calculó la tasa de informalidad laboral para cada una de las 32 entidades federativas, agrupándolas en cinco categorías, desde muy alta a muy baja informalidad. Los estratos de construyeron por el método de desviaciones estándar.

En primer lugar se observa que en los estados del sur, caracterizados por ser los de mayor pobreza y marginación, se localizan las mayores tasas de informalidad laboral. En efecto, el estrato de muy alta informalidad se encuentran las tres entidades de mayor marginación según los indicadores del Consejo Nacional de Población, CONAPO (2015): Oaxaca, con un 80\% de informalidad, Guerrero con $79.5 \%$ y Chiapas con $78.8 \%$. En tanto, las entidades federativas del norte, que se destacan por ser las de menores grados de pobreza y marginación y de más alta competitividad, se localizan las tasas más bajas. En el estrato más bajo de informalidad laboral se encuentran: Coahuila (con una tasa de 35.1\%), Chihuahua (36\%), Nuevo León (36.9\%), Baja California (40.1\%), y Baja California Sur (40.4\%). La Ciudad de México (CDMX, antes DF), que en anteriores encuestas se encontraba en el nivel más bajo pasó, en la encuesta de 2015, al lugar 13, con una tasa de 51.3\%, ubicándose así en el segundo estrato, de baja informalidad, a nivel nacional.

Mapa 1

\section{MÉXICO: Tasas de Informalidad Laboral por Entidad Federativa, 2015.}

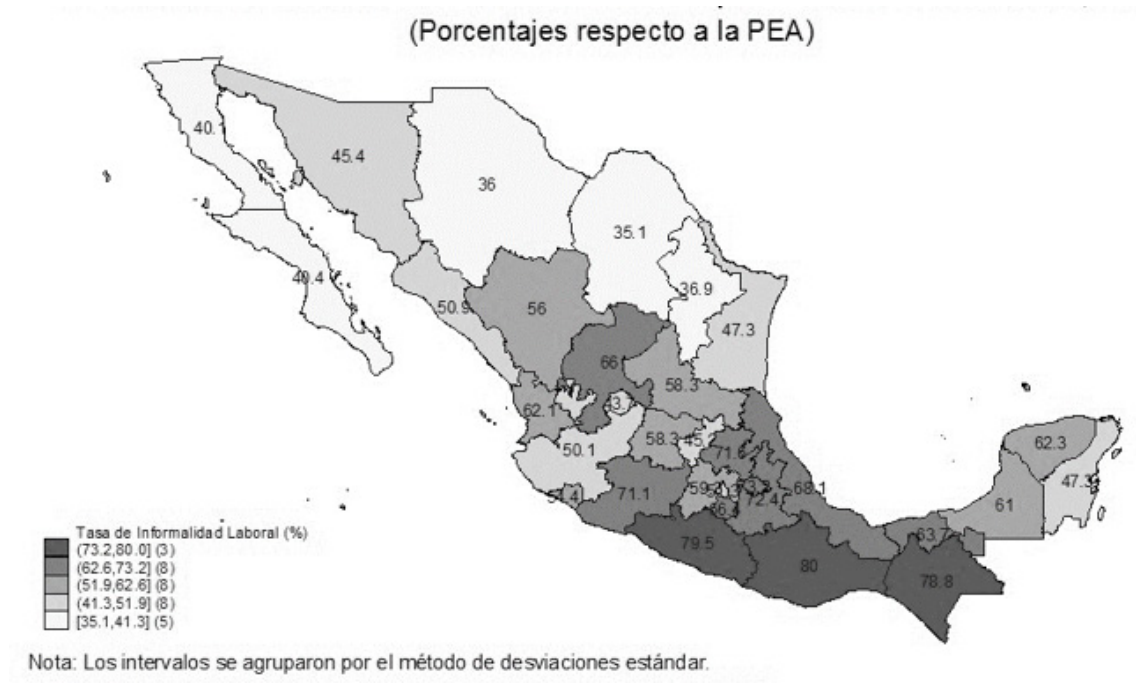

Fuente: Elaboración propia con microdatos de ENOE, 2015.

Lo que muestra el mapa 1 es una asociación, muy marcada, entre la tasa de informalidad laboral con el grado de marginación por entidad federativa. Esto puede demostrarse fácilmente si se obtiene el coeficiente de correlación entre esas dos variables. El cuadro 2 muestra un coeficiente 
de correlación, entre la tasa de informalidad y el grado de marginación, positivo y muy alto (de 0.8358), estadísticamente significativo (a menos del 1\%). Esto quiere decir que a medida que aumenta el grado de marginación y pobreza, la tasa de informalidad laboral es mayor. ${ }^{5}$

La relación entre informalidad y pobreza corrobora una de las hipótesis fundamentales de este trabajo: la informalidad laboral está muy asociada al grado de precarización del trabajo, medido por el índice de marginación de las entidades federativas. Sin duda este es un efecto del funcionamiento de los mercados de trabajo en zonas de bajo desarrollo: en aquellas regiones en donde priva la mayor marginación y pobreza, la población ocupada busca insertarse en el mercado laboral aún en condiciones de informalidad, y esto a su vez por la incapacidad de la economía de ofrecer empleos formales a los ocupados, lo cual es congruente con lo explicado por Rodarte desde el año 2003: "México no tiene la capacidad de ofrecer empleos bien remunerados y dentro del marco legal" (Rodarte, 2003).

Cuadro 2

\section{MÉXICO: Matriz de correlaciones de la tasa de informalidad laboral, el índice de margina- ción y la tasa de desocupación, entre entidades federativas, 2015*/}

\begin{tabular}{|l|c|c|c|}
\hline & $\begin{array}{c}\text { Tasa de informalidad } \\
\text { laboral }\end{array}$ & $\begin{array}{c}\text { Índice de } \\
\text { marginación }\end{array}$ & Tasa de desocupación \\
\hline $\begin{array}{l}\text { Tasa de informalidad } \\
\text { laboral }\end{array}$ & 1.0000 & 1.0000 & \\
\hline Índice de marginación & 0.8358 & & \\
\hline Tasa de desocupación & -0.5553 & -0.6745 & 1.0000 \\
\hline & $(0.0010)$ & $(0.0000)$ & \\
\hline
\end{tabular}

*/ Por debajo de los coeficientes de correlación calculados se muestran, entre paréntesis, los niveles de significancia.

Fuente: elaboración propia con datos de la ENOE y del CONAPO 2015.

\subsection{Informalidad y desempleo.}

La baja capacidad de la economía de México para crear empleos formales, genera otro efecto más: su asociación negativa con la tasa de desocupación. Esta asociación negativa entre informalidad laboral y tasa de desocupación puede ser observada si se correlacionan las dos tasas para cada una de las 32 entidades federativas del país, tal y como se mostró en el cuadro 2 . El coeficiente fue de -0.5553, que si bien puede ser considerado como correlación "media”, fue estadísticamente significativa al $0.1 \%$. El signo negativo expresa la relación inversa entre la tasa de desocupación y la

5 En el cuadro 2 se presenta también la correlación con la tasa de desempleo porque más abajo se retomará el tema. 
de informalidad laboral, lo cual significa que, el desempleo es bajo porque la población labora en actividades informales (ver gráfica 2).

Entidades federativas como Guerrero (Gro) y Oaxaca (Oax), con las tasas de desocupación más bajas que el resto del país, 2.0 y $2.4 \%$ respectivamente, enfrentan la mayor tasa de informalidad laboral, 80.0 y $78.8 \%$ respectivamente. El resto de las entidades con tasas de desocupación de entre 2 y $3 \%$ muestran grados de informalidad laboral superiores al 60\%. En el otro extremo, cuando las tasas de desocupación son muy altas, del 5\% o más, las de informalidad laboral apenas rebasan el 50\%, siendo sólo tres estados mexicanos la excepción: Tabasco (Tab), Nayarit (Nay) y Estado de México (Mex), quienes aun presentando tasas de informalidad relativamente altas, también muestran tasas de desempleo muy cercanas al máximo nacional, que es de 6 por ciento.

Gráfica 2

MÉXICO: Relación entre informalidad laboral y desempleo por entidad federativa, 2015.

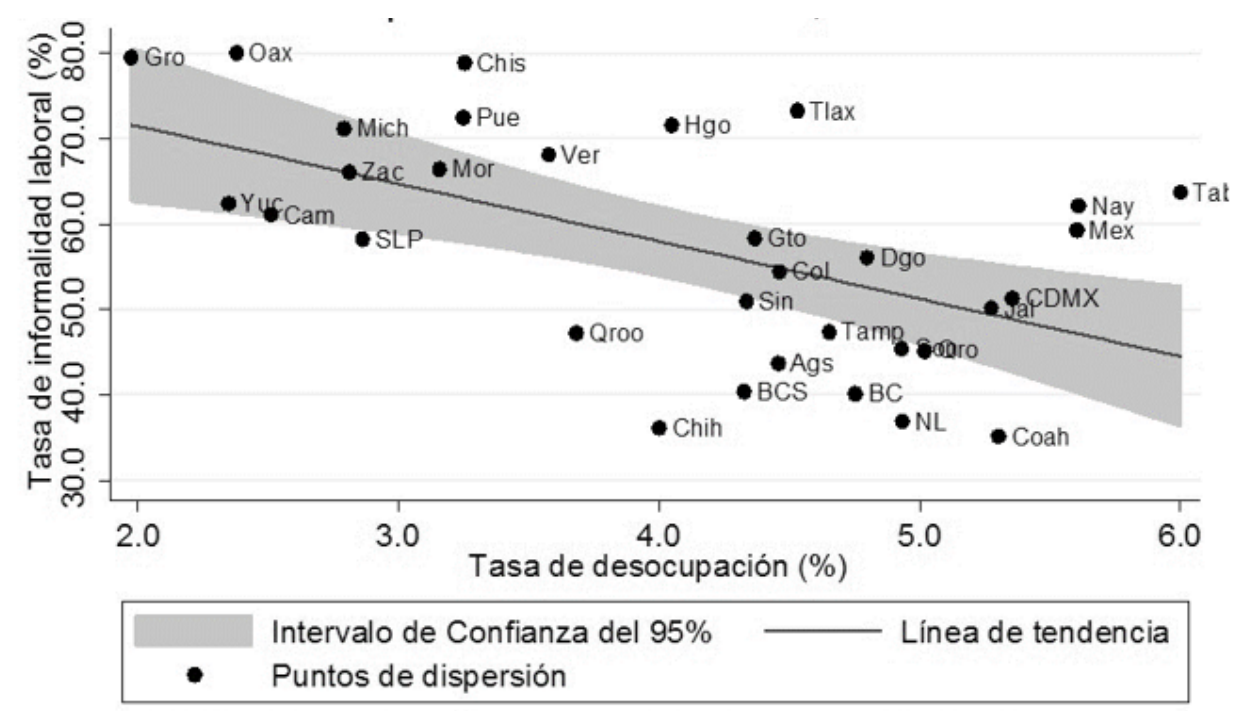

Fuente: Elaboración propia con microdatos de ENOE, 2015.

Las diferencias entre norte y sur del país nuevamente son notorias. En los estados del norte se registran las más bajas tasas de informalidad laboral, pero las más altas en desempleo: Coahuila (Coah), Nuevo León (NL), Baja California (BC), Baja California Sur (BCS), Tamaulipas (Tamp), Sonora (Son) y Jalisco (Jal), así como algunos otros estados del centro del país: Ciudad de México (CDMX), Querétaro (Qro) y Aguascalientes (Ags). En los del sur y sureste la situación se invierte: bajas tasas de desocupación pero alta informalidad, ya se mencionaron Guerrero y Oaxaca, pero también, destacan en esta situación: Chiapas (Chis), Puebla (Pue), Veracruz (Ver), Morelos (Mor), Michoacán (Mich), Zacatecas (Zac), Yucatán (Yuc) y Campeche (Cam). San Luis Potosí (SLP), que 
está en una ubicación centro-norte del país, aparece junto con este grupo de entidades.

Al parecer esta fuerte asociación entre desempleo e informalidad se presenta de manera más evidente en épocas de crisis. En la gráfica 3 se muestra cómo, en 2009, el año de la gran crisis financiera que azotó a la economía mexicana, la correlación fue la más alta del período 2005-2015, llegando a -0.6742 , lo cual es fácilmente explicable debido a la gran pérdida de empleos formales que se presenta en la economía ante una crisis. La alternativa de ocupación para una gran parte de la población mexicana es la informalidad, y aunque ésta ha venido disminuyendo de manera notoria desde 2009, el coeficiente de correlación sigue siendo alto, lo cual podría ser un indicio de que la economía sigue sin recuperarse desde el año de la gran crisis, o a que no se ha puesto, por parte de las políticas públicas, el suficiente interés en reducir la informalidad laboral por la vía de la generación de empleos formales.

Gráfica 3

MÉXICO: Correlación entre desempleo e informalidad. 2005-2015* (Coeficiente de correlación de Pearson, calculado anualmente)

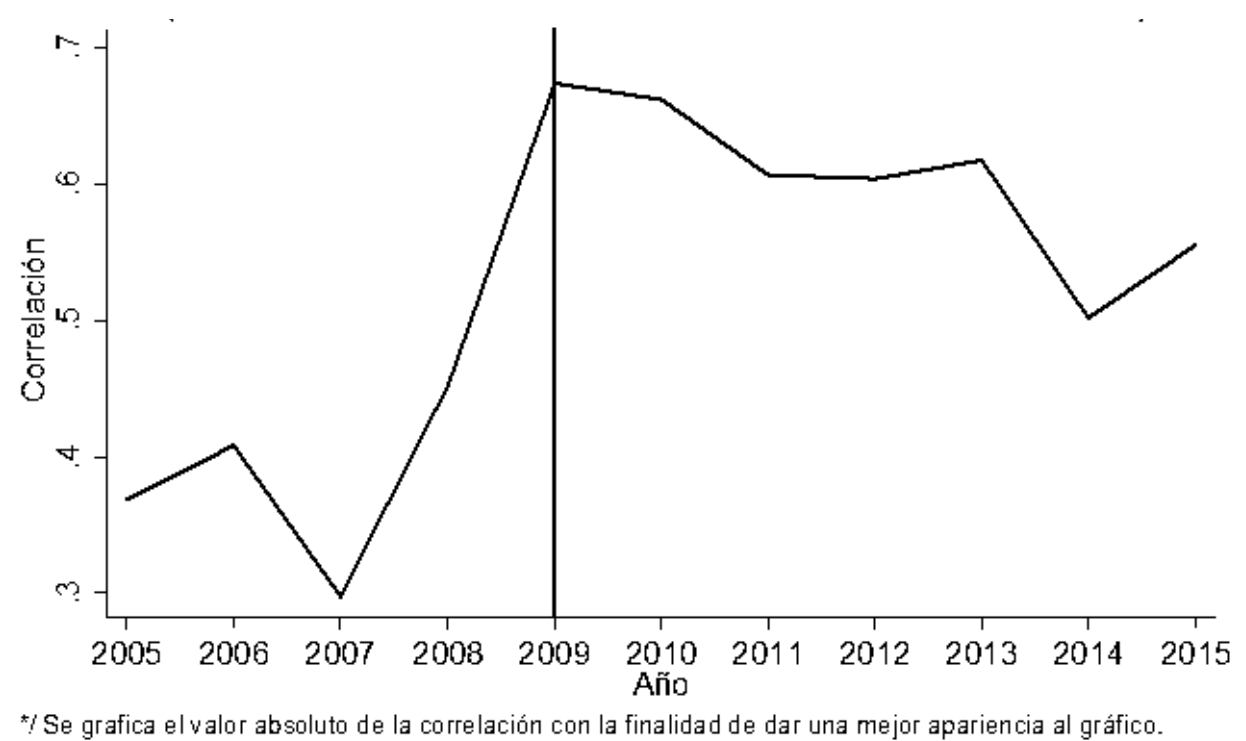

Fuente: Elaboración propia con microdatos de ENOE. 


\section{$\rightarrow$ 4. Determinantes individuales de la informalidad laboral.}

El objetivo de esta sección es analizar, con métodos econométricos, las características individuales de los trabajadores ocupados en la informalidad laboral. Se busca comprobar si las diferencias en género, edad, y escolaridad, entre otras, determinan o no la participación de los ocupados en la informalidad laboral.

Podría esperarse que, debido a que la informalidad está asociada a un alto grado de precarización laboral, los grupos considerados como vulnerables sean los más propensos a optar por la informalidad laboral. Se entiende por grupos vulnerables a todos aquellos que, ya sea por su edad, raza, sexo, condición económica, características físicas, circunstancia cultural o política, se encuentran en mayor riesgo de que sus derechos sean violentados (Pérez, C. M., 2005, pp. 849-853). La falta de acceso o límites que impone el mercado laboral a un trabajo decente es lo que en principio podría considerarse como en riesgo de que sea violado. ${ }^{6}$

Desde esta perspectiva y con base en la información disponible y contenida en ENOE, se incluyeron las siguientes variables como posibles determinantes de la informalidad laboral: la condición de género, tener o no hijos, edad, escolaridad y ubicación geográfica del trabajador ocupado.

Podría esperarse el siguiente patrón de comportamiento de estas características en la determinación de la informalidad laboral:

1. La mujeres podrían ser más propensas que los hombres a participar en la informalidad laboral debido a la segregación (o autosegregación) laboral que las presiona (o incentiva) a buscar trabajos dentro del hogar, ello les permitiría estar al pendiente del cuidado de éste y de los hijos, sobre todo si son pequeños (menores de 6 o 14 años) en caso de que los tuvieran.

2. Los trabajadores ocupados más jóvenes y los adultos maduros (mayores de 65 años), podrían ser más propensos a la informalidad laboral debido a las restricciones que el mercado formal les impone, por la falta de experiencia de trabajo en el primer caso, y por el desgaste de las condiciones físicas y de salud en el segundo.

3. Los trabajadores con más bajas dotaciones de formación escolar podrían ser los más propensos a la informalidad laboral que aquellos con mayor formación, porque los trabajos asociados a la baja o nula escolaridad son los más asociados con la precarización. A mayor

6 Para la OIT, trabajo decente significa la oportunidad de acceder a un empleo productivo que genere un ingreso justo, la seguridad en el lugar de trabajo y la protección social para las familias, mejores perspectivas de desarrollo personal e integración social, libertad para que los individuos expresen sus opiniones, se organicen y participen en las decisiones que afectan sus vidas, y la igualdad de oportunidades y trato para todos, mujeres y hombres (OIT, s.f., 1. http://www.ilo.org/global/topics/decent-work/lang-es/index.htm). Nótese entonces la similitud del concepto de la OIT con el de precarización laboral que a lo largo de este artículo ha venido desarrollándose. 
educación el trabajador se inserta con relativa mayor facilidad al mercado primario (o moderno) en el lenguaje de los teóricos de la segmentación laboral.

4. El grado de pobreza y marginación de la población ocupada, como ya se explicó previamente, es un determinante significativo de la participación de la población ocupada en la informalidad, debido a la asociación que existe de ésta con la precarización de la población y las condiciones de trabajo.

La técnica que se utiliza para realizar el análisis es la regresión tipo probit. En ésta, la variable dependiente puede ser dicótoma, tomando el valor de 1 si el individuo en cuestión asume la característica de interés, en nuestro caso, la participación del trabajador en la informalidad laboral, y 0 si es formal. Debido a esa característica, de que la variable dependiente es dicótoma, el modelo se interpreta como la estimación de la probabilidad de que $\mathrm{Y}$ tome el valor de 1, dado un conjunto de características individuales X. El modelo de regresión probit toma entonces la siguiente forma:

$$
Y_{i}=\operatorname{Pr}\left(Y_{i}=1 \mid X_{i}\right)=\Phi\left(Z_{i}\right)=\int_{-\infty}^{Z_{i}} \phi(s) d(s)+u_{i}
$$

En donde $\phi(s)=\frac{1}{\sqrt{2 \pi}} e^{-s^{2} / 2}$ es la función de densidad de probabilidad normal, $\mathrm{Z}_{\mathrm{i}}$ define la combinación lineal siguiente: $Z_{i}=\boldsymbol{X} \boldsymbol{\beta}+\boldsymbol{u}$ es una matriz de características individuales de cada uno de los incluidos en la muestra, y $\boldsymbol{\beta}$ es el vector de parámetros desconocidos a estimar, que miden el impacto de las características individuales en la probabilidad de que el individuo sea un ocupado informal, s es una variable "muda" de integración con media cero y varianza uno, y $\boldsymbol{u}_{i}$ representa el término de error estocástico del modelo de regresión. ${ }^{7}$

Como se observa, existe una relación no lineal de la variable dependiente Y con los parámetros del modelo y por lo tanto no puede usarse el método de mínimos cuadrados para la estimación del modelo, se utiliza así el llamado método de máxima verosimilitud, el cual estima los parámetros $\beta$ que maximizan la función de verosimilitud (probabilidad) que relaciona la matriz de características $\mathrm{X}$ con la probabilidad de que $\mathrm{Y}=1$.

\subsection{Especificación y estimación del modelo de participación en la informalidad laboral.}

La variable dependiente se define como sigue:

$Y_{i}=1$ si el ocupado es informal

$Y_{i}=0$ si es formal

Desde $i=1, \ldots, \mathrm{n}$ individuos en la muestra

7 La exposición del modelo de regresión probit y la nomenclatura que se utilizó en este documento se tomó de Cabrer (2001).

- Economía, Población y Desarrollo. Cuadernos de Trabajo de la UACJ, núm. 35, sep-oct 2016 
Las variables independientes son las siguientes: sexo ( $1=$ hombre, $0=$ mujer), edad (en años), escolaridad (en años terminados), hijos (es una variable indicativa de si las mujeres declararon tener hijos), región (es la clasificación en 5 niveles de marginación, que va desde 1 = Muy Baja, hasta 5 = Muy Alta).

Se incluye la variable sexo para probar la significancia estadística de la mayor participación de las mujeres en la informalidad laboral en relación a los hombres. En efecto, de acuerdo a los datos proporcionados por la ENOE (2015), las mujeres tienen una mayor participación en la informalidad laboral, de $58.6 \%$ contra $57.3 \%$ de los hombres.

La tasa de informalidad laboral de los ocupados es muy alta en el caso de los jóvenes, y va reduciéndose conforme aumenta la edad, sin embargo, esta reducción llega a un mínimo para posteriormente incrementarse de nueva cuenta a medida que los ocupados rebasan los 45 años, situación que se hace más notoria a partir de los 56 años de edad (ver gráfica 4). Esta es la razón por la que la variable edad debe introducirse al modelo de manera tanto lineal como no lineal, es decir, como $e d a d+e d a d^{2}$, esperándose que el coeficiente cuadrático sea positivo debido a la concavidad hacia arriba de la curva de la informalidad laboral respecto a la edad.

Cabe señalar que las mujeres conforme tenga mayor número de hijos, incrementan la posibilidad de emplearse en la informalidad, ello debido a la posibilidad de que el empleo informal otorgue mayor flexibilidad en cuanto a horas de trabajo y lugar para desempeñarse. Estas probabilidades varían también en el caso de que los hijos de las mujeres sean pequeños, menores de 6 años. Se incluirá por lo tanto una variable indicativa de si las mujeres tienen hijos. Las tasas de informalidad laboral de las mujeres, según el número de hijos que tienen, se muestran en la siguiente gráfica 5.

Es importante mencionar que la tendencia cada vez mayor hacia la informalidad a medida que aumenta el número de hijos podría estar correlacionada con la edad de las mujeres. En efecto, podría ser muy probable que las mujeres con más de 4 o 5 hijos tengan edades superiores al límite de los 45 (señalado más arriba), y que por ese hecho, de edad y no por los hijos, se incorporen más fácilmente en la informalidad que en la formalidad, de ahí que se haga una estimación (modelo 3) restringiendo la muestra al grupo de personas de entre 25 y 45 años. 
Gráfica 4

Tasa de informalidad por categorías de edad

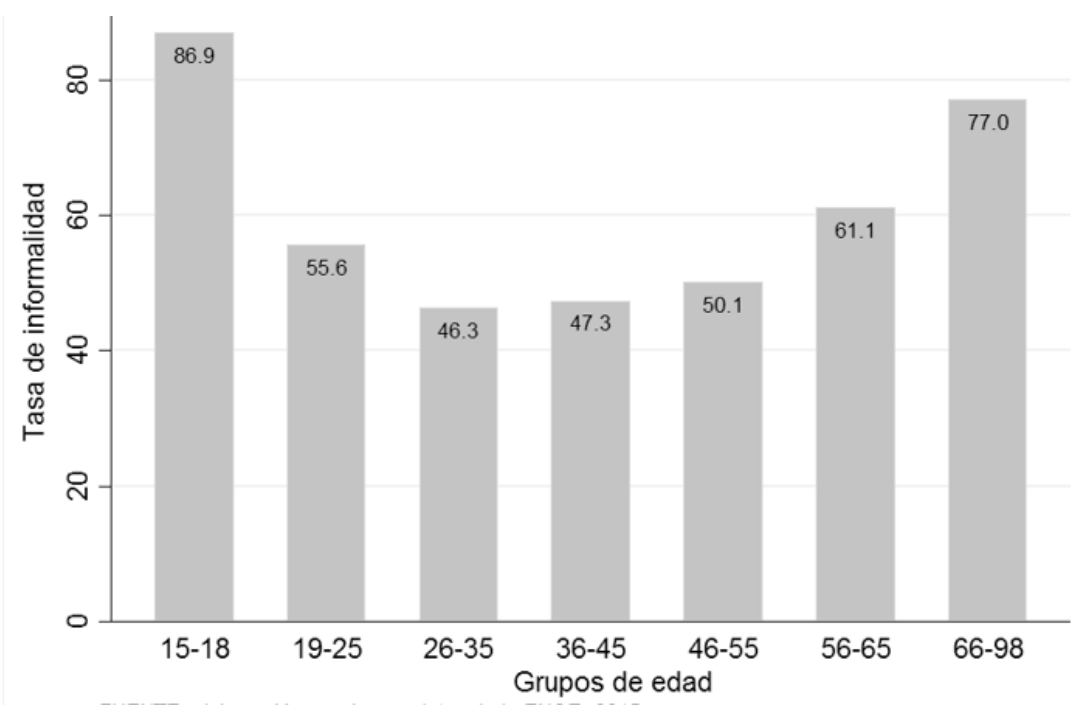

Fuente: Elaboración propia con datos de la ENOE, 2015.

Gráfica 5

Probabilidad de ser informal de acuerdo al númeo de hijos (En mujeres)

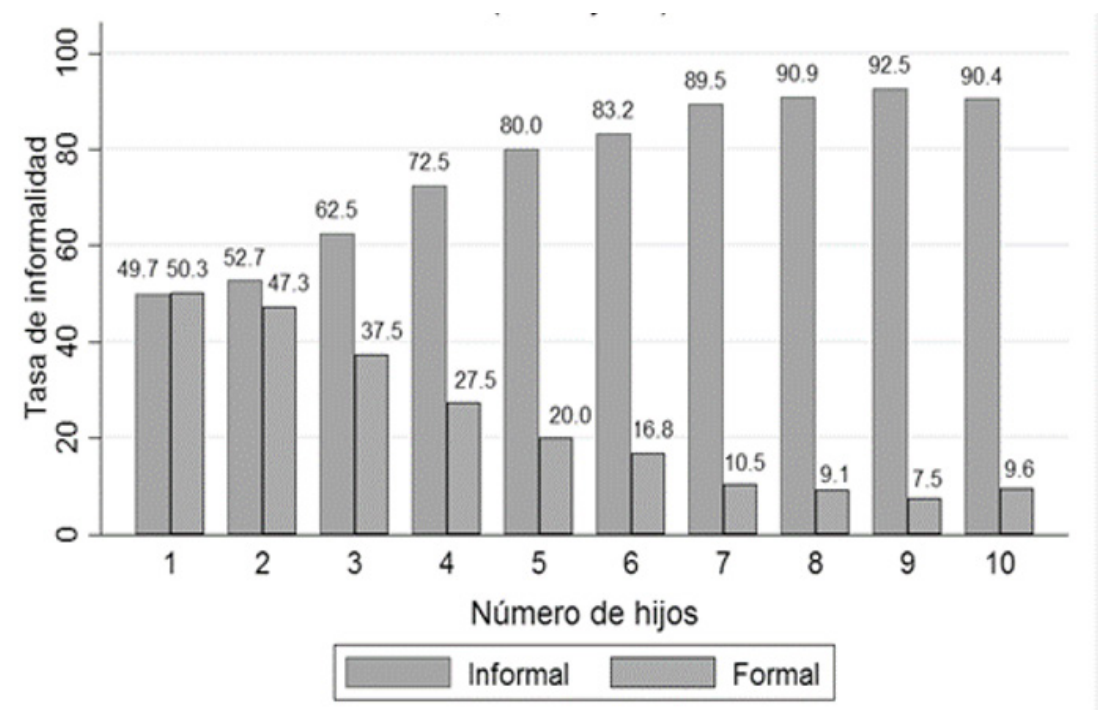

Fuente: Elaboración propia de datos de la ENOE, 2015. 
Otra variable independiente incluida es la escolaridad, es importante agregarla al modelo porque las personas con nivel de educación alto, son menos probables que se desempeñen en la informalidad. Recordemos que el mercado primario o moderno de la economía (asociado al mercado laboral formal), se caracteriza con perfiles de mano de obra calificada o de mayor formación escolar. Una evidencia de ello se muestra en la siguiente gráfica 6.

Gráfica 6

\section{Tendencia de la tasa de informalidad respecto a la educación}

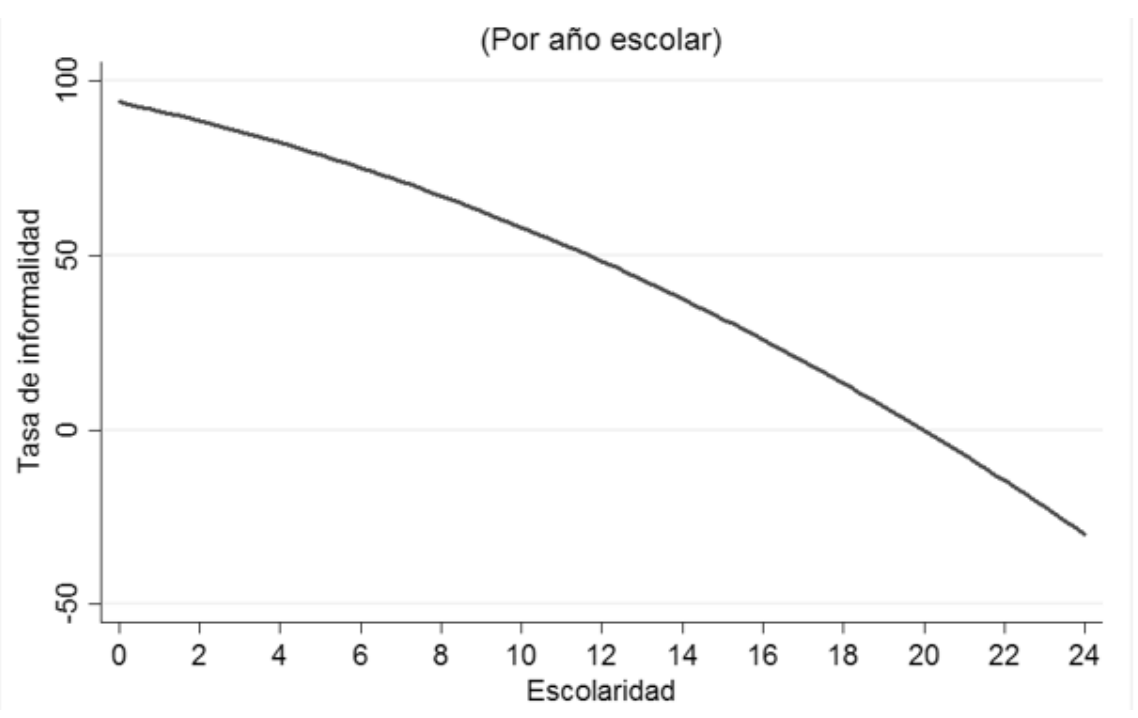

Fuente: Elaboración propia de datos de la ENOE, 2015.

Por último la variable región según grado de marginación es cualitativa, se divide en cinco clasificaciones: muy baja, baja, media, alta y muy alta. En el cuadro 3 se muestra la agrupación de las entidades federativas según su grado de marginación. La relación que se espera se explicó previamente: las personas que viven en la región con muy alta marginación, estarían más propensas a desempeñarse en un empleo informal, en cambio, las que habitan en la región con muy baja marginación, su posibilidad de encontrarse en el sector informal disminuye. 
Cuadro 3

Tendencia de la tasa de informalidad respecto a la educación

\begin{tabular}{|c|l|}
\hline $\begin{array}{c}\text { Región según grado de } \\
\text { marginación }\end{array}$ & \multicolumn{1}{c|}{ Entidades que la conforman } \\
\hline Muy alta & -Guerrero, Chiapas y Oaxaca \\
\hline Alta & $\begin{array}{l}\text {-Veracruz, Hidalgo, San Luis Potosí, Puebla, Campeche, } \\
\text { Tabasco, Michoacán y Yucatán }\end{array}$ \\
\hline Media & $\begin{array}{l}\text {-Nayarit, Zacatecas, Guanajuato, Durango, Tlaxcala, } \\
\text { Querétaro, Sinaloa, Quintana Roo y Morelos }\end{array}$ \\
\hline Baja & $\begin{array}{l}\text {-México, Tamaulipas, Chihuahua, Baja California Sur, } \\
\text { Colima, Sonora, Jalisco y Aguascalientes }\end{array}$ \\
\hline Muy baja & -Coahuila, Baja California, Nuevo León y Distrito Federal \\
\hline
\end{tabular}

Fuente: Elaboración propia con datos del CONAPO, 2015.

Del 100\% de los ocupados sólo en la región de muy baja marginación $56.30 \%$ son formales y el resto (43.70\%) son informales. Para la región con baja marginación, los informales se incrementan significativamente, representando el $48.50 \%$ del total de los ocupados. Esta tendencia se mantiene hasta llegar al estrato de muy alta marginación, en donde la distribución entre formales e informales fue de $20.59 \%$ y $79.41 \%$, respectivamente (ver cuadro 4 ).

Cuadro 4

Porcentaje de trabajadores formales e informales por región según grado de marginación, 2015

\begin{tabular}{|c|c|c|c|}
\hline Nivel de marginación & Formal & Informal & Total \\
\hline Muy baja & 56.30 & 43.70 & 100.00 \\
\hline Baja & 48.50 & 51.50 & 100.00 \\
\hline Media & 40.89 & 59.11 & 100.00 \\
\hline Alta & 31.76 & 68.24 & 100.00 \\
\hline Muy alta & 20.59 & 79.41 & 100.00 \\
\hline Total & 42.19 & 57.81 & 100.00 \\
\hline
\end{tabular}

Fuente: Elaboración propia con datos de la ENOE, 2015.

El modelo resultante a estimar, con base en la información previa, se especifica un primer modelo (Modelo 1) o modelo básico, de la siguiente manera:

$$
\begin{aligned}
& Y_{i}=\int_{-\infty}^{Z_{i}} \frac{1}{\sqrt{2 \pi}} e^{-s^{2} / 2} d(s)+u_{i}=\Phi\left(Z_{i}\right)+u_{i}= \\
& =\Phi\left(\beta_{0}+\beta_{1} X_{1 i}+\beta_{2} X_{2 i}+\beta_{3} X_{3 i}^{2}+\beta_{4} X_{4 i}+\sum_{j=1}^{p} \beta_{j} X_{5 i p}\right)+u_{i \operatorname{an}} \quad \mathrm{i}=1, \ldots \mathrm{n}
\end{aligned}
$$

En donde: 
$Y_{i}=1$ si el individuo en la muestra es un ocupado informal, 0 si es formal

$X_{1 i}=\operatorname{Sexo}=1$ si es hombre, 0 si es mujer

$X_{2 i}=E d a d$ del individuo i (en años)

$X_{3 i}^{2}=E d a d^{2}$ del individuo $i$

$X_{4 i}=$ Escolaridad (en años completados)

$X_{5 i p}=$ Nivel de marginación al que corresponde el individuo i dado el estrato (de marginación) $\mathrm{j}$, en

donde $\mathrm{j}=1$ si el individuo corresponde al nivel de marginación "Muy Bajo", 2 "Bajo", 3 "Medio", 4

"Alto" y 5 "Muy alto", se refiere entonces a una variable cualitativa con $\mathrm{p}(5)$ categorías.

$u_{i}=$ Término de error aleatorio

Adicionalmente a este modelo (Modelo 1), se especificaron dos más. En el Modelo 2 se estimó el impacto de la participación en la informalidad laboral de las mujeres con hijos y sin hijos, en comparación con los hombres en general. Y finalmente, en el Modelo 3, se tomó solo la muestra de ocupados cuyas edades van de los 25 a los 45 años, ello con el objetivo de aislar el sesgo por edad en la participación en la informalidad laboral. En efecto, dado que los ocupados muy jóvenes o con edades superiores a los 45 años se les dificulta el acceso a la economía formal, se toma el sub grupo de la población considerada en edad con menores dificultades (menor riesgo, o menos vulnerable) para ingresar al mercado de trabajo en calidad de ocupados formales.

Los resultados se presentan en el cuadro 5. No se muestran los coeficientes obtenidos directamente de la estimación probit, sino los efectos marginales, ello con el objetivo de que los coeficientes sean fácilmente interpretados como impactos en las probabilidades de ser un ocupado informal respecto a la variable $\mathrm{Xi}$, y en el caso de las variables dummies, como la diferencia en la probabilidad de que el ocupado participe en la informalidad laboral entre las dos características definidas por la variable dummie. Se observa que todos los coeficientes son estadísticamente significativos al 1\%, y la pseudo-R2 muy cercana a $0.2(0.17)$, lo cual es suficientemente alta y significativa para datos transversales. 


\section{Cuadro 5}

\section{Resultados de tres modelos Probit de participación en la informalidad laboral (Efectos marginales)}

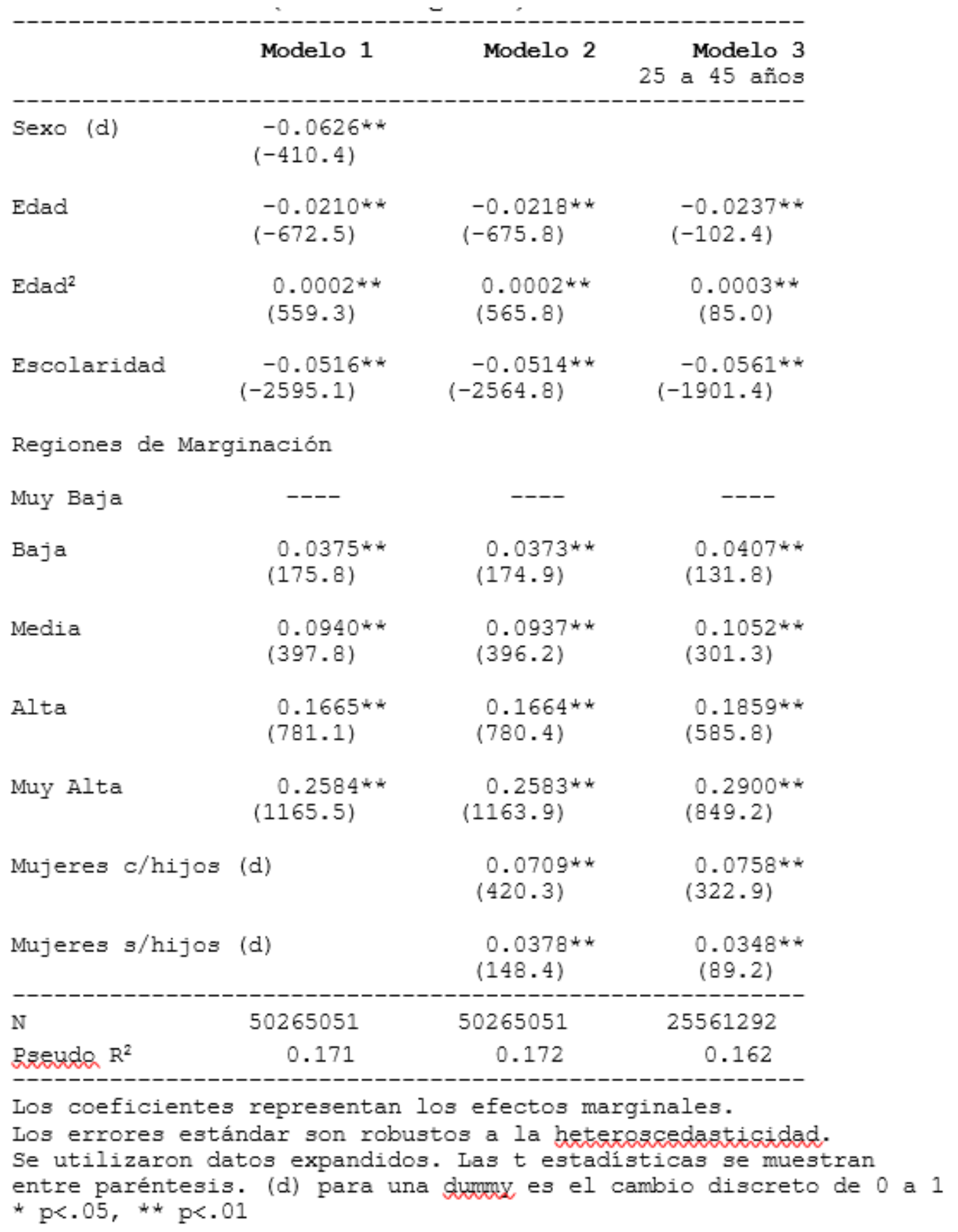




\subsection{Interpretación de resultados.}

Los modelos estimados probaron que las diferencias en el género, edad, escolaridad y ubicación del ocupado según la región de marginación, son determinantes significativos de la probabilidad de ser informal.

El modelo 1, el más general, probó que los hombres tienen 6.26\% menos de probabilidad que las mujeres de ser informales; que a medida que aumenta la edad del ocupado, se reduce en $2.1 \%$ esa probabilidad, pero a la vez, aumenta, por cada año, en $0.02 \%$, de ahí la concavidad de la curva de participación en la informalidad laboral. La mínima probabilidad de participar en la informalidad se lograría entre los 26 y los 35 años de edad (gráfica 4). A medida que aumenta la escolaridad de las personas se reduce, por cada año más, en 5.16\% la probabilidad de estar en la informalidad. Y por último, en comparación con la región de más baja marginación, los que viven en entidades de "baja" marginación aumentan esa probabilidad en 3.75\%, los de marginalidad "media", en $9.4 \%$, los de "alta" marginación en $16.65 \%$, y por último, los ocupados que trabajan en las entidades federativas de "muy alta" marginación son los que tienen las más altas probabilidades de participar en la informalidad, de $25.84 \%$ en comparación con la región de "muy baja" marginación.

En el Modelo 2, se sustituyó la variable sexo por dos variables de interacción, indicativas de la condición de ser mujer y tener o no tener hijos. Al incluirlas al modelo se entiende que la categoría base (o de comparación) son los hombres. De esa manera se encontró que las mujeres con hijos, son el grupo con mayores probabilidades de participar en la informalidad, siguiendo en importancia las mujeres sin hijos y por último los hombres. En efecto, las mujeres con hijos se estima que tienen 7.1\% más de probabilidad de participar en la informalidad laboral que los hombres; en tanto, las mujeres sin hijos es de 3.78\%. El resto de los coeficientes del modelo 2 son muy similares al 1.

Finalmente, en el Modelo 3, en el que se tomó únicamente a la muestra de la población de 25 a 45 años de edad, los coeficientes estimados son muy similares a los del modelo 1 y del 2 . Simplemente aumentó ligeramente la diferencia en las probabilidades de participar en la informalidad laboral de las mujeres con hijos y las de sin hijos. Se demostró que las probabilidades de participar en la informalidad son mayores para las mujeres con hijos, y menores para las mujeres sin hijos en comparación con los resultados del modelo 2. En este modelo 3 se subraya nuevamente que se están comparando mujeres y hombres con características de edad similares, pertenecientes al grupo en donde la probabilidad de inserción al mercado laboral es la más alta posible. 


\section{5. Conclusiones.}

Una de las preocupaciones más importantes de la política pública en materia de empleo, ha sido el tamaño de la informalidad laboral, básicamente porque su crecimiento repercute en los niveles de recaudación fiscal (cuando se trata de informalidad de unidades económicas, o sector informal) y en la calidad del empleo (informalidad laboral) que además de precarizar las condiciones de vida de los ocupados mexicanos, comprime el nivel de demanda agregada total de la economía.

En esta investigación se explicó el concepto de informalidad laboral, señalando que, hasta el año 2012, el INEGI definía la informalidad desde un enfoque de sector informal. Este enfoque se centra en las características de las unidades económicas no agropecuarias que no se constituyen como empresas y que no cumplen con los registros más básicos que la legislación demanda de proveedores de bienes y servicios. (INEGI, 2014, p. 3). Pero a partir de 2012, con base en las recomendaciones de la OIT, derivadas particularmente de la Decimoséptima Conferencia Internacional de Estadísticos del Trabajo, llevada a cabo en 2003, se incorporó el concepto de informalidad laboral, en el cual se incluyó, además de los considerados en el sector informal (definición previa a 2012), el llamado enfoque de condiciones laborales, el cual aplica a los trabajadores subordinados remunerados (asalariados, por comisión, y/u honorarios) así como a los trabajadores familiares que participan en la actividad económica sin tener un acuerdo de remuneración monetaria. "Los trabajadores bajo esta situación pueden estar recibiendo un salario o manejando la relación laboral como si fuera mercantil (trabajadores por comisión u honorarios) pero el hecho es que, como también sucede en el servicio doméstico, no pueden hacer efectivos ciertos derechos laborales (seguridad social, beneficios no salariales, liquidación o finiquito al término de la relación de trabajo) ni tener acceso a las instituciones de salud comprendidas dentro de esos derechos. Estos casos no caen dentro del ámbito del Sector Informal, porque la empresa o institución para las que aportan sus servicios están perfectamente constituidas como tales o, como mínimo, el negocio ya está registrado ante la autoridad fiscal." (INEGI, 2014, pp. 5-6).

Durante el período que va de 2005 a 2015, el porcentaje de personas ocupadas en condición de informalidad, se ha mantenido cercano al 60\% (tasa de informalidad laboral). Si bien es cierto que desde el tercer trimestre del 2012 esta tasa de informalidad laboral ha decrecido en al menos dos puntos porcentuales, también ha sido notorio el crecimiento del desempleo. En efecto, la evidencia empírica de nuestro país muestra que, en cuando la informalidad es alta, la desocupación baja, y viceversa, cuando la informalidad se reduce, el desempleo aumenta. Esto es así debido al severo problema estructural que enfrenta el mercado de trabajo mexicano, que se refleja en una fuerte incapacidad para generar empleos formales. Si la informalidad no existiera, el desempleo se elevaría a tasas muy superiores al 5\% (como las que actualmente se sitúa). El énfasis que en 
los últimos años ha puesto el gobierno, sobre todo con las recientes reformas a la Ley Federal del Trabajo, de reducir la informalidad, incrementa el riesgo de la población de caer en desempleo, o de plano, aumentar el volumen de población no económicamente activa disponible, llamada también, por diversos analistas laborales, desempleo disfrazado.

Existe una relación estadísticamente significativa entre informalidad laboral por entidad federativa y grado de marginación, observándose que, mientras mayor sea esta marginación, la informalidad laboral aumenta, lo cual refuerza la hipótesis de que las personas en condiciones de pobreza y ante la incapacidad de la economía para generar empleos formales, buscarán opciones de sobrevivencia laboral en el mercado secundario, o informal. Esta dinámica genera una especie de "círculo vicioso" que profundiza las condiciones de pobreza o precarización de la población trabajadora.

Con microdatos de la ENOE de 2015, se analizaron las características individuales de los ocupados que podrían incidir en la propensión de optar o pertenecer a la informalidad laboral. Estas características individuales, disponibles en la encuesta, y que por hipótesis determinan la probabilidad de pertenencia a la informalidad laboral fueron: sexo, edad, escolaridad (medida en años terminados), grado de marginación de la entidad federativa del ocupado y, en el caso de las mujeres, tener o no hijos.

Como resultado de la aplicación de un modelo econométrico tipo probit, se encontraron los siguientes resultados:

1. Los hombres tienen $6.26 \%$ menos de probabilidad que las mujeres de ser informales. Son varios los factores que afectan el hecho de que la mujer sea más vulnerable a ser informal que un hombre, tal vez el más significativo es el tener hijos y la cantidad de éstos, puesto que, conforme la mujer tenga mayor número de hijos, la ocupación en la informalidad favorece una mayor flexibilidad en cuanto horas de trabajo y lugar para desempeñarse, esto es, puede ocuparse -laboralmente- en el hogar, sin que esto represente descuido de los hijos o de su hogar.

2. A medida que aumenta la edad del ocupado, se reduce en $2.1 \%$ esa probabilidad, pero a la vez, aumenta, por cada año, en $0.02 \%$, de ahí la concavidad de la curva de participación en la informalidad laboral. La mínima probabilidad de participar en la informalidad se lograría entre los 26 y los 35 años de edad. Los menores de 25 no consiguen un trabajo formal debido a que las empresas formales argumentan falta de experiencia laboral, además que sus capacidades intelectuales están en formación; por otra parte, los mayores de 45 años, o en el extremo, de 65 años, se enfatiza el deterioro de sus habilidades y capacidades laborales para obtener un empleo digno en el sector formal. 
3. Por cada año más de escolaridad que tiene la población ocupada, se reduce en $5.16 \%$ la probabilidad de ser informal. Así, se demuestra que una mayor educación o formación escolar posibilita a los trabajadores acceder al mercado o segmento del mercado laboral primario (moderno), en donde prevalece el empleo formal y una mayor calidad de éste.

4. A medida que aumenta el grado de marginación de las entidades federativas, aumentan las probabilidades de los trabajadores de ocuparse como informales. Los resultados mostraron que, en comparación con la región de "muy baja" marginación, los de "baja" marginación aumentan sus probabilidades de participar en la informalidad en $3.75 \%$, los de "media marginación" en 9.4\%, los de "alta" en $16.65 \%$ y, finalmente, los de "muy alta" marginación, en 25.88 por ciento.

Estos resultados pueden variar ligeramente según el modelo especificado y estimado, pero las diferencias son mínimas.

Se probó además el impacto sobre la probabilidad de pertenecer en la informalidad laboral de las mujeres con y sin hijos, obteniéndose que las mujeres con hijos son el grupo con mayores probabilidades de participar en la informalidad en comparación con las mujeres sin hijos y del total de los hombres. En efecto, las mujeres con hijos se estima que tienen 7.1\% más de probabilidad de participar en la informalidad laboral que los hombres; en tanto, para las mujeres sin hijos esta probabilidad es de $3.78 \%$.

Las grandes desventajas que tienen los trabajadores en el sector informal son:

a) la falta de prestaciones, como bien se señaló en éste artículo el $77.74 \%$ de los informales no cuenta con ningún tipo de prestación, el $20.84 \%$ no tiene prestación en materia de salud pero si a otras prestaciones, y el restante $1.42 \%$ no especificó. En contra parte el $95.08 \%$ del sector formal cuenta con acceso a instituciones de salud y a otras prestaciones, el $4.92 \%$ restante solo cuenta con prestaciones en materia de salud;

b) Ingresos bajos, el ingreso promedio mensual de un trabajador informal es de 3 mil 639 pesos mientras que el promedio mensual para el trabajador formal es de 7 mil 72 pesos;

c) En relación a las horas de trabajo por semana, el trabajador formal en promedio trabaja más porque tiene horas fijas establecidas por la empresa, organización, institución, etc. de acuerdo a la jornada legal promedio, que va de 40 a 48 horas, en cambio el trabajador informal en promedio trabaja menos, porque las condiciones laborales son más flexibles. Así, los trabajadores formales tienen una jornada promedio semanal de 45 horas, y los informales de 38 horas. 
Un comentario final que merece nuestra atención, es el relativo a la necesidad de combatir la informalidad laboral, porque de esa manera se enfrenta la precarización laboral de los trabajadores ocupados en México, y se ofrecen las condiciones para aumentar el nivel de demanda agregada que nuestra economía requiere para crecer. Sin embargo, las políticas públicas han fallado en lo general, puesto que enfrentan la informalidad laboral por el lado de las unidades económicas, o empresas informales a través de los mecanismos institucionales de control y vigilancia fiscal (Sistema de Administración Tributaria, SAT). Generalmente, las micro y pequeñas empresas optan por la informalidad como una estrategia de supervivencia. El pago de impuestos representa para muchas de ellas un alto costo, y por lo tanto, les reduce las posibilidades de supervivencia en el mercado. La formalización de estas empresas, obligaría a seguir manteniendo en la informalidad y la precarización salarial a sus trabajadores, es decir, que aunque las unidades económicas se formalicen, sus trabajadores seguirían sin disponer de seguridad social y prestaciones de ley por el oneroso costo que para las empresas en desventaja (recordar que 98\% de las unidades económicas en México son micro y pequeñas) representaría. Basta con observar lo que sucede en una gran parte de estas unidades económicas: se ofrece al trabajador la posibilidad de otorgársele seguro social pero a cambio de reducir su ingreso. Lo mismo sucede con el resto de prestaciones de las que, generalmente, no son otorgadas: reparto de utilidades, primas vacacionales, permisos varios con goce de sueldo, entre otros.

Para combatir la informalidad sectorial y laboral, debe recuperarse la capacidad de crecimiento económico, y por ende, de generación de empleos. Las limitaciones al crecimiento económico y a la generación de empleos se encuentran en el agotamiento del modelo de crecimiento hacia afuera que se puso en marcha desde principios de la década de los ochenta en México. Se debe recurrir entonces al fortalecimiento del mercado interno por medio de la elevación de los niveles de demanda que incentiven la inversión. Ello no significa que no se deban aprovechar las ventajas de la apertura comercial y la atracción de inversión extranjera, sino que en paralelo, se fortalezca el mercado interno mexicano, se elaboren y apliquen políticas industriales, y se eleve el nivel de consumo y de vida de los sectores sociales y de trabajadores pobres. 
Anexo 1

Tabla de abreviaciones de las entidades federativas de México

\begin{tabular}{|c|c|c|}
\hline Número & Entidad & Abreviación \\
\hline 1 & Aguascalientes & Ags \\
\hline 2 & Baja California & $\mathrm{BC}$ \\
\hline 3 & Baja California Sur & $\mathrm{BCS}$ \\
\hline 4 & Campeche & Cam \\
\hline 5 & Coahuila & Coah \\
\hline 6 & Colima & $\mathrm{Col}$ \\
\hline 7 & Chiapas & Chis \\
\hline 8 & Chihuahua & Chilh \\
\hline 9 & Ciudad de México & CDMX \\
\hline 10 & Durando & Dge \\
\hline 11 & Guanajuato & Gto \\
\hline 12 & Guerrero & Gro \\
\hline 13 & Hidalgo & Hge \\
\hline 14 & Jalisco & $\mathrm{Jal}$ \\
\hline 15 & México & Mex \\
\hline 16 & Michoacán & Mich \\
\hline 17 & Morelia & Mor \\
\hline 18 & Nayarit & Dax \\
\hline 19 & Nuevo León & $\mathrm{NL}$ \\
\hline 20 & Oaxaca & Qax \\
\hline 21 & Puebla & Pue \\
\hline 22 & Querétaro & Qro \\
\hline 23 & Quintana Roo & Qrog \\
\hline 24 & San Luis Potosí & SLP \\
\hline 25 & Sinaloa & $\operatorname{Sin}$ \\
\hline 26 & Sonora & Son \\
\hline 27 & Tabasco & Tab \\
\hline 28 & Tamaulipas & Tamp \\
\hline 29 & Tlaxcala & Ilax \\
\hline 30 & Veracruz & Ver \\
\hline 31 & Yucatán & Yue \\
\hline 32 & Zacatecas & Zac \\
\hline
\end{tabular}

Anexo 2

Tabla de abreviaturas

\begin{tabular}{|c|l|}
\hline CEPAL & Comisión Económica para América Latina y el Caribe \\
\hline CIET & Conferencia Internacional de Estadísticos del Trabajo \\
\hline CONAPO & Consejo Nacional de Población \\
\hline CUCEA & Centro Universitario de Ciencias Económico Administrativas \\
\hline ENOE & Encuesta Nacional de Ocupación y Empleo \\
\hline INEGI & Instituto Nacional de Estadística y Geografia \\
\hline OIT & Organización Internacional del Trabajo \\
\hline PEA & Población Económicamente Activa \\
\hline PREALC & Programa Regional del Empleo para América Latina y el Caribe \\
\hline STPS & Secretaría de Trabajo y Prevención Social \\
\hline SAT & Sistema de Administración Tributaria \\
\hline TIL & Tasa de Informalidad Laboral \\
\hline
\end{tabular}




\section{Bibliografía y referencias documentales}

Antón, A. (2006). Precariedad laboral e identidades juveniles. Fundación Sindical de Estudios.

Cabrer, B., Sancho, P., \& Serrano, D. (2001). Microeconometría y decisión. Madrid, España: Piramide.

CEPAL. (2006, enero 13). Revista de la CEPAL no.88 [Text]. Recuperado el 2 de mayo de 2016, a partir de http://www.cepal.org/es/publicaciones/37475-revista-la-cepal-no88

CONAPO. (2015). Datos abiertos del Índice de Marginación. Consejo Nacional de Población. Recuperado a partir de http://www.conapo.gob.mx/en/CONAPO/Datos_Abiertos_del_Indice_de_Marginacion

Hart, K. (1973). Informal income opportunities and urban employment in Ghana. The journal of modern African studies, 11(01), 61-89.

INEGI. (2014). La informalidad laboral. Encuesta Nacional de Ocupación y Empleo. Marco conceptual y metodología. Instituto Nacional de Geografía y Estadística.

Klein, E., \& Tokman, V. E. (1988). Sector informal: una forma de utilizar el trabajo como consecuencia de la manera de producir y no viceversa. A propósito del artículo de Portes y Benton. Estudios sociológicos, 205-212.

Lewis, W. A. (1979). The Dual Economy Revisited. The Manchester School, 47(3), 139-191.

OIT. (s.f.). Trabajo decente. Recuperado el 18 de junio de 2016, a partir de http://www.ilo.org/ global/topics/decent-work/lang--es/index.htm,

OIT. (2014). El empleo informal en México: situación actual, políticas y desafíos. Programa de promoción de la formalización en América Latina y el Caribe. Recuperado a partir de www.oil.org

Pedrero-Nieto, M. (2009). Las condiciones de trabajo a principios del siglo XXI. Presencia de las mujeres en el sector informal. Papeles de población, 15(59), 119-171.

Pérez, C. M. (2005). Aproximación a un estudio sobre vulnerabilidad y violencia familiar. En Boletín Mexicano de Derecho Comparado (Vol. 113). México, DF.: Instituto de Investigaciones Jurídicas de la UNAM.

Perry, G. E. (2008). Informalidad: escape y exclusión. Banco Mundial. Recuperado a partir de http://www.funtrab.org.pa/uploads/informalidad_bm_2007_res\%C3\%BAmen.pdf

Rodarte, R. (2003). Experiencias en la medición del sector informal en México, (23), 70.

Rodgers, G. (2002). El trabajo decente como una meta para la economía global. CINTERFOR/ OIT. Recuperado a partir de http://ilo-mirror.library.cornell.edu/public/spanish/region/ampro/cinterfor/publ/boletin/153/pdf/rodger.pdf

Ruesga, S., \& Fujii, G. (2006). El comportamiento del mercado de trabajo en América Latina en el contexto de la globalización económica. Recuperado a partir de http://escholarship.org/uc/ item/3xn8j42k.pdf

Sethuraman, S. V. (1981). The urban informal sector in developing countries: employment poverty and environment. Recuperado a partir de http://www.popline.org/node/411103

Tokman, V. E. (2001). De la informalidad a la modernidad, 24, 9-32. 


\section{Números anteriores:}

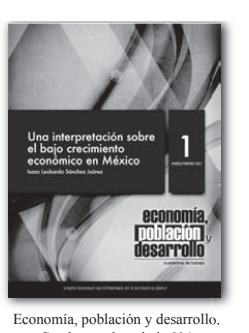

Economía, población y desarrollo
Cuadernos de trabajo №1

Enero-Febrero 2011

Una interpretación sobre el bajo
crecimiento económico en Méxice

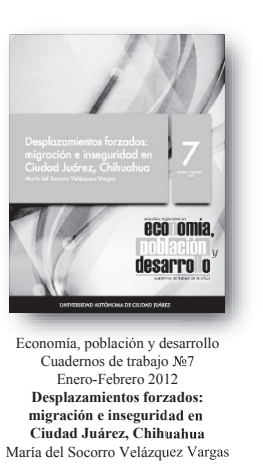

Ciudad Juárez, Chihuahua
Maria del Socorro Veläquez Vargas

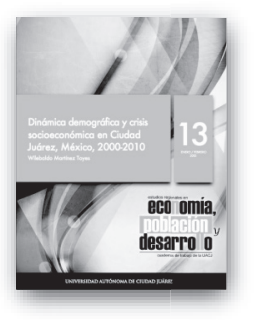

Economía, población y desarrollo
Cuarednos de trabajo № 13 ńmica demogŕfica y

fica y crisis

México, 2000-2010
Wilebaldo Martinez Toyes
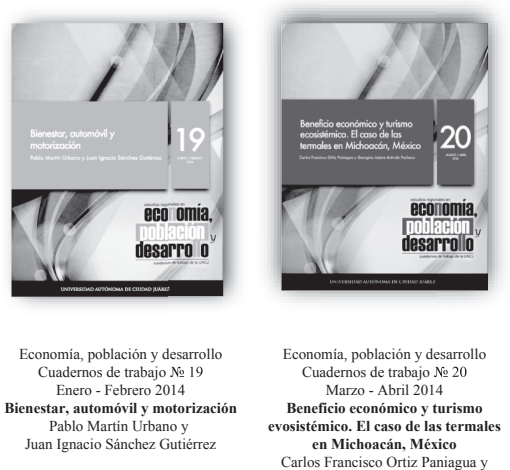
Carlos Francisco Ortizi Paniagua y
Georgina Jatzire Arévalo Pacheco
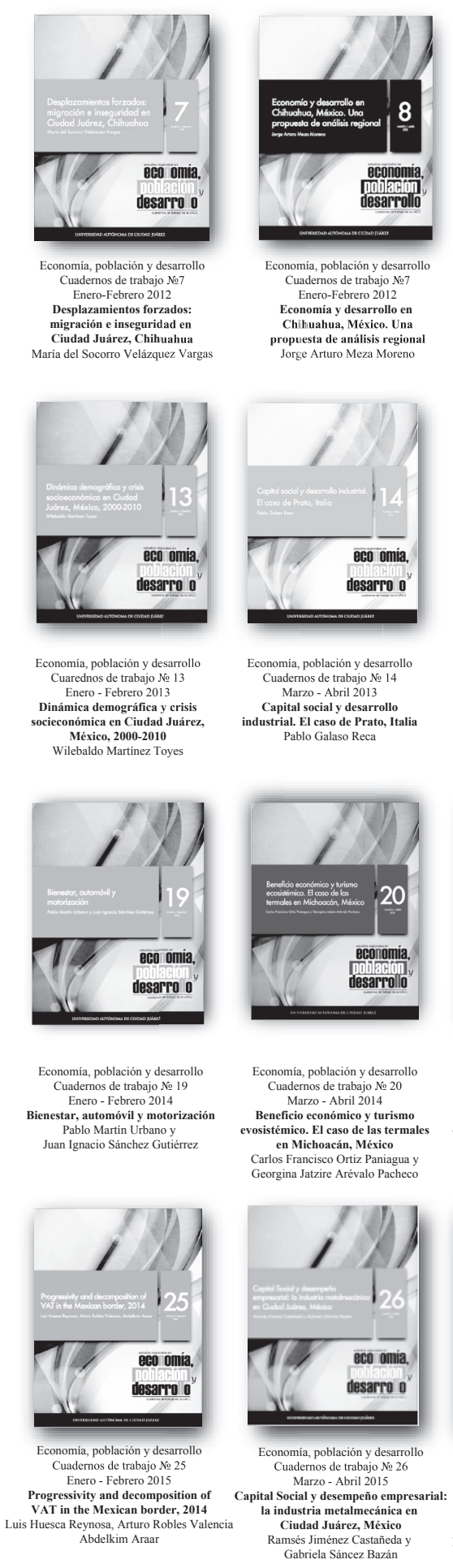

Economía, población y desarrollo
Cuadernos de trabajo № 14

Capital social y desarrollo

strial. El caso de Prato, It

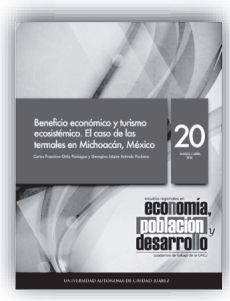

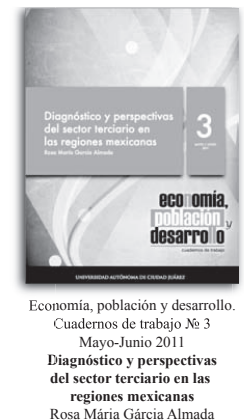
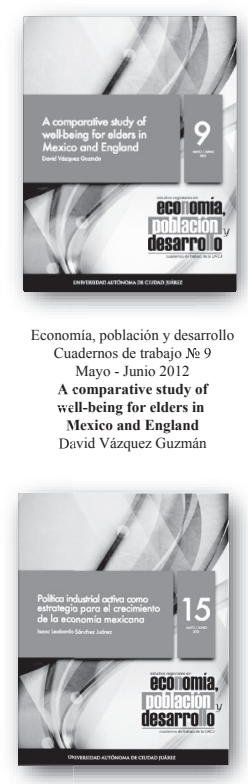

Economía, población y desarrollo
Cuadernos de trabajo № 15

Política industrial activa como de la economia mexicana
Isaac Leobardo Sánchez Juárez
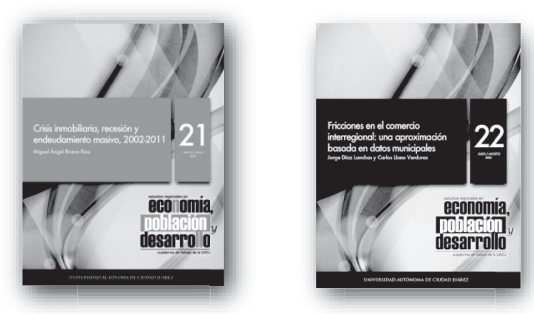

Economía, población y desarrol
Cuadernos de trabajo № 21 Mayo - Junio 2014 Crisis inmobiliaria, recesión y
endeudamiento masivo, 2002 -2011 Miguel Ángel Rivera Rios
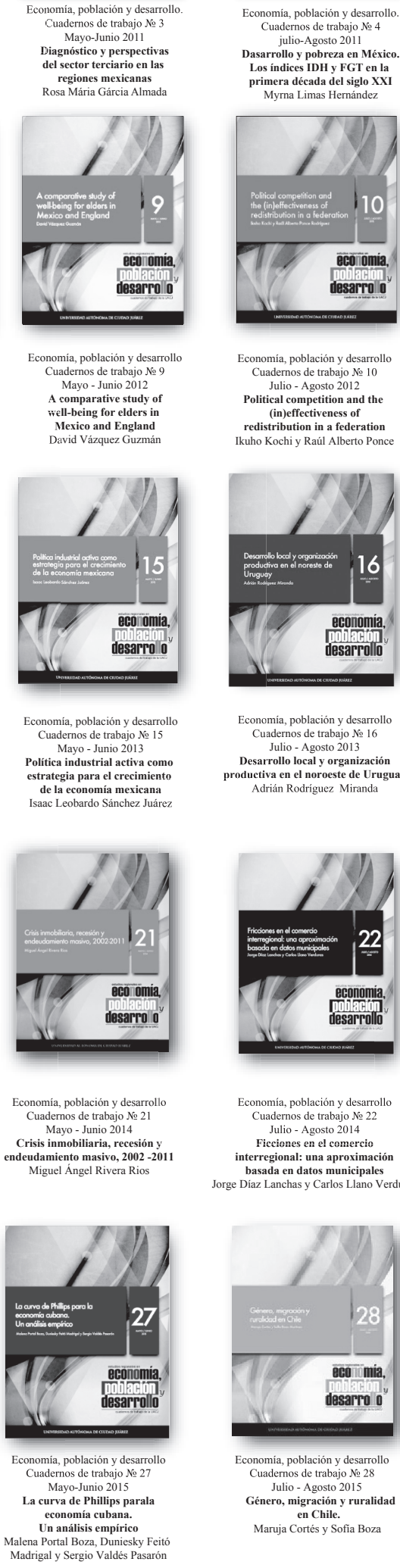

julio-Agosto 2011
rollo y pobreza en

Dasarrollo y pobreza en México.
Los indices IDH y FGT en la primera década del siglo XXI

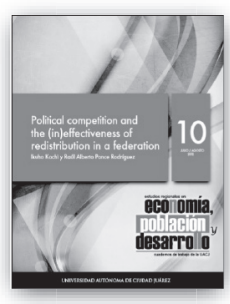

Economía, población y desarrollo Cuadernos de trabajo № 10
Julio - Agosto 2012 Political competition and the redistribution in a federation
lkuho Kochi y Raúl Alberto Ponce

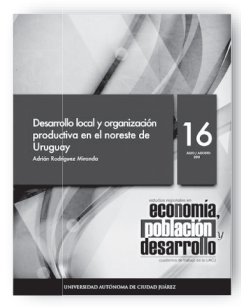

Economía, población y desarrollo
Cuadernos de trabajo № 16

Desarrollo local y organización
productiva en el noroeste de Urugua
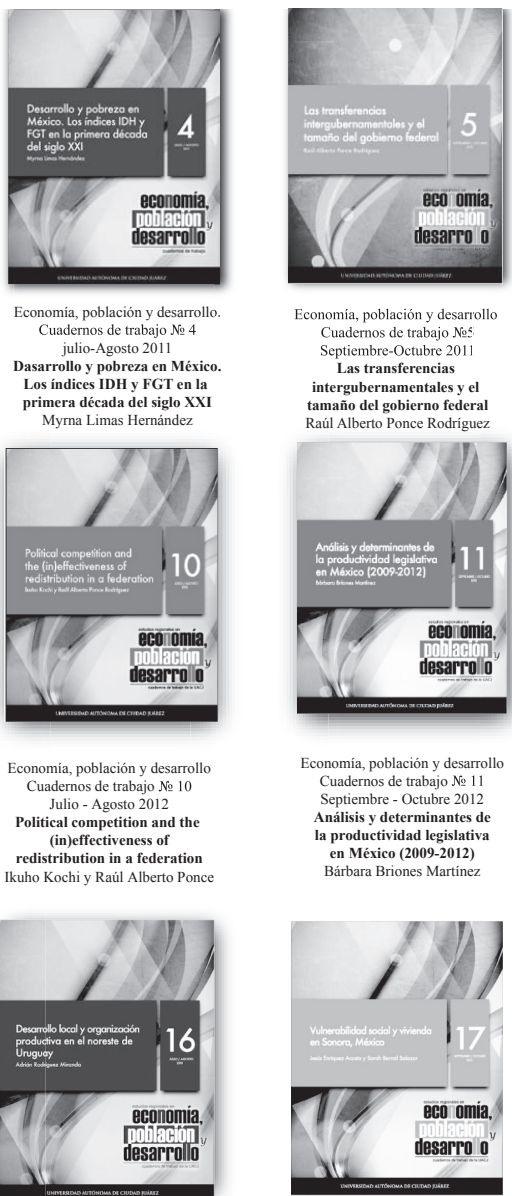

Adrián Rodriguez Miranda

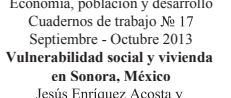
Jesús Enríquez Acosta y
Sarah Bernal Salazar

conomía, población y desarrollo
Cuadernos de trabajo №5
Septiembre-Octubre 2011

Septiembre-Octubre 205
Las transferencias

intergubernamentales $\mathrm{y}$ el
tamaño del gobierno federal

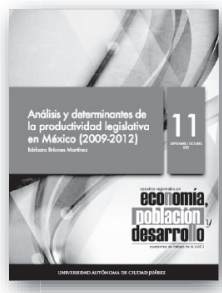

Economía, población y desarrollo

Cuadernos de trabajo № 11

Análisis y determinantes de en México (2009-2012)
entis

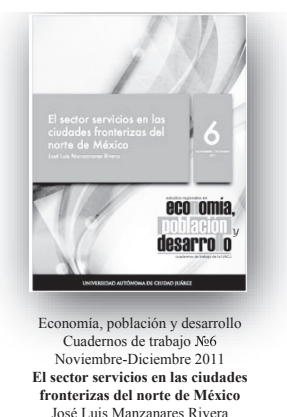

José Luis Manzanares Rivera

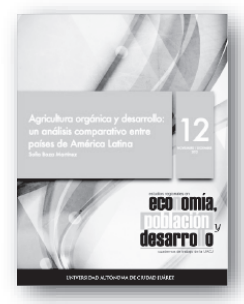

Economía, población y desarrollo Noviembre - Diciembre 2012

un analisis comparativo entre

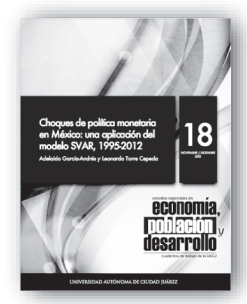

Cunomia, población y desarrollo Cuadernos de trabajo № 18

Choques de politica monetaria en México: una aplicación del
modelo SVAR, 1995-2012
Adelaido García-Andés y Leonardo Torre Ce
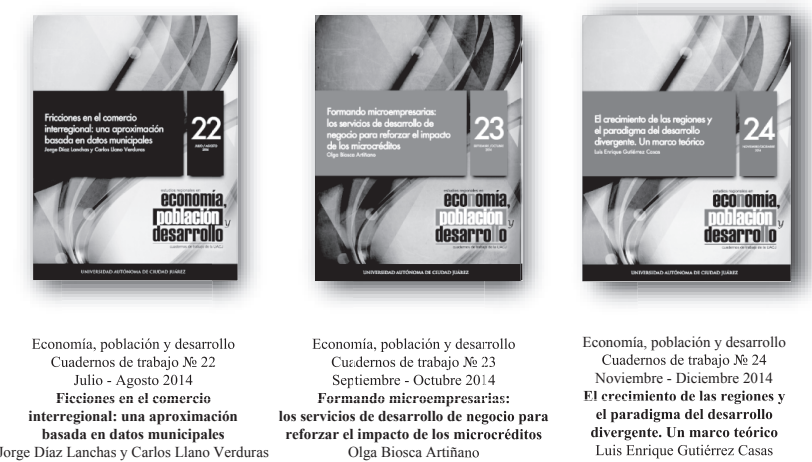

Cuadernos de Noviembre - Diciembre 2014 El crecimiento de las regiones $y$ el paradigma del desarrollo
divergente. Un marco teórico Luis Enrique Gutiérrez Casas
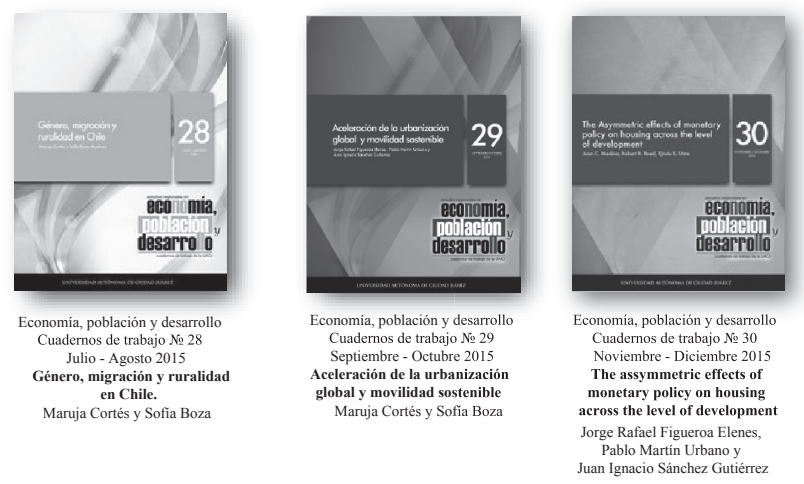


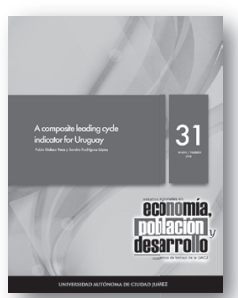

Economiá, población y desarrollo

Cuadernos de trabajo № 31

A composite leading cycle

indicator for Uruguay

Pablo Galaso Reca y
Sandra Rodriguez López

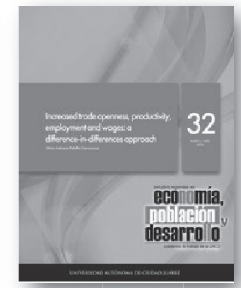

Economía, población y desarrollo

Cuadernos de trabajo № 32

Marzo - Abril 2016
Increased trade openness, productivity,
employment and wages:

a difference-in-differences approac

Silvia Adriana Peluffo Geronazzo

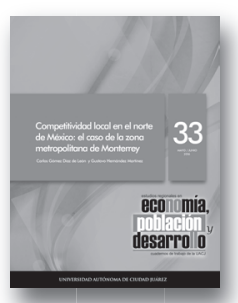

Economía, población y desarrollo Cuadernos de trabajo № 33

Mayo - Junio 2016
Competitividad local en el norte
de México: el caso de la zona

metropolitana de Monterrey

Carlos Gómez Diaz de Leén y
Gustavo Hernández Martinez

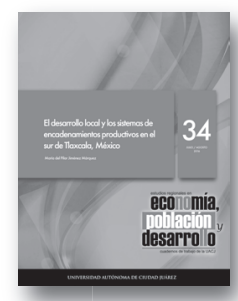

Economía, población y desarrollo

Cuademos de trabajo № 44
Julio - Agosto 2016

El desarrollo local y

productivos en el sur de

Tlaxcala, México
Tlaction 


\section{$\rightarrow$ Normas Editoriales}

\section{Para el documento general:}

Tipo de letra: Times New Roman.

Tamaño: 11 puntos.

Interlineado: 1.5 espacios.

Títulos y subtítulos:

El texto principal en 11 puntos. Títulos 12 puntos (en resaltado). Subtítulos 11 puntos. Cada título y subtítulo deberá numerarse bajo el siguiente orden: $1,1.1,2,2.1,2.2 \ldots$

La extensión máxima de los cuadernos de trabajo será de 40 cuartillas.

La primera vez que se emplee una sigla en el texto se especificará primero su equivalencia completa y después la sigla.

\section{Hoja de presentación:}

Título:

14 puntos, centrado, resaltado.

Nombre de autor(es):

12 puntos

Resumen y abstract:

Debe incluir resumen en español y abstract (diez puntos), no mayor a 250 palabras

Palabras clave:

Incluir entre tres y cinco palabras clave, en español e inglés

Referencia del autor o autores:

Institución de adscripción, grado académico y líneas-grupos de investigación que desarrolla y a los que pertenece.

\section{Sistema de referencia de citas:}

Harvard-APA

Las citas bibliográficas en el texto deberán incluir entre paréntesis sólo el apellido del autor, la fecha de publicación y el número de página; por ejemplo: (Quilodrán, 2001: 33).

\section{Notación en sección de bibliografía y fuentes de información:}

Se deberá incluir al final del texto. Toda referencia deberá estar mencionada en el texto o notas de pie de página.

Cada referencia iniciará con el primer apellido o los apellidos, luego el nombre del autor, y después, entre paréntesis, el año de publicación seguido de un punto. Ejemplos:

Se deberá incluir al final del texto. Toda referencia deberá estar mencionada en el texto o notas de pie de página.

Cada referencia iniciará con el primer apellido o los apellidos, luego el nombre del autor, y después, entre paréntesis, el año de publicación seguido de un punto. Ejemplos:

Artículo:

Ros, Jaime (2008). "La desaceleración del crecimiento económico en México desde 1982”, en Trimestre Económico, vol. 75, núm. 299, pp. 537-560.

Libro:

Villarreal, René (2005). Industrialización, competitividad y desequilibrio externo en México. 
Un enfoque macroindustrial y financiero (1929-2010), México, Fondo de Cultura Económica. Capítulo de libro:

Castillo, Manuel Ángel (2003). "La política de inmigración en México: un breve recuento", en Manuel Ángel Castillo, Alfredo Lattes y Jorge Santibáñez (coords.), Migración y fronteras, Tijuana, El Colegio de la Frontera Norte / Asociación Latinoamericana de Sociología / El Colegio de México, pp. 425-451.

\section{Notas de pie de página:}

Se utilizarán para hacer indicaciones complementarias, aclaraciones o ampliación de una explicación. La notas de pie de página en Times New Roman, 10 puntos.

\section{Tipología de imágenes dentro del texto:}

Cuadro

Gráfica

Diagrama

Mapa

Figura

Todas las imágenes deben ser numeradas y mencionadas dentro del texto. A toda imagen debe incluirse la fuente.

Las indicaciones de la imagen: tipo y número de imagen, título de imagen y fuente se escriben en 10 puntos. En el texto poner como imagen los mapas, figuras, gráficas y diagramas -con el ánimo de no perder el formato realizado por el autor.

\section{Ecuaciones y fórmulas:}

Si se utilizan ecuaciones o fórmulas deberá utilizarse el editor de ecuaciones de Word y numerarse.

\section{Envío de trabajos}

Los trabajos deben ser enviados a la dirección de correo: lgtz@uacj.mx. Con el Dr. Luis Enrique Gutierrez Casas, editor de esta publicación.

La aceptación de cada colaboración dependerá de la evaluación de dos dictaminadores especialistas en la materia que se conservarán en el anonimato, al igual que el autor (autores) para efectos de la misma. 


\section{$\rightarrow$ Editorial Guidelines}

\section{For General Document:}

Font type: Times New Roman.

Size: font size 11 .

Paragraph: 1.5 line spacing.

Titles and subtitles: Main text font size 11. Titles font size 12 (Bold). Subtitles font size 11.

Each title and subtitle should be numbered in the following order: 1, 1.1, 2, 2.1, 2.2...

The maximum length of the workbooks will be 40 pages.

The first time an abbreviation is used in the text will be specified first complete equivalence and then stands.

\section{Front cover:}

Title:

Font size 14, centered, Bold.

Author name(s):

Font size 12.

Abstract:

It should include abstract in Spanish and abstract (font size 10), no more than 250 words.

Keywords:

Include three to five keywords, in Spanish and English.

Reference of author:

Institution of affiliation, academic degree and line-developed by research groups and belonging.

\section{Bibliographical appointment system:}

Harvard-APA

Citations in the text should include between parentheses only the author's name, publication date and page number, for example:

(Quilodrán, 2001: 33).

\section{Notation about Bibliography section and Information fonts:}

Should be included at the end of the text. All references must be mentioned in the text or footnotes page.

Each reference starts with the first name or last name, then the name of the author, and then, in parentheses, the year of publication followed by a period. Examples:

Article:

Ros, Jaime (2008). “La desaceleración del crecimiento económico en México desde 1982”, en Trimestre Económico, vol. 75, núm. 299, pp. 537-560.

Book:

Villarreal, René (2005). Industrialización, competitividad y desequilibrio externo en México. Un enfoque macroindustrial y financiero (1929-2010), México, Fondo de Cultura Económica.

Book chapter:

Castillo, Manuel Ángel (2003). "La política de inmigración en México: un breve recuento”, en Manuel Ángel Castillo, Alfredo Lattes y Jorge Santibáñez (coords.), Migración y fronteras, Tijuana, E1 Colegio de la Frontera Norte / Asociación Latinoamericana de Sociología / El Colegio de México, pp. 425-451. 


\section{Footnotes:}

Must be used to make additional indications, clarification or expansion of an explanation. The footnotes must be in Times New Roman, font size 10.

\section{Image typology inside text:}

Picture

Graph

Diagram

Map

Figure

All images must be numbered and mentioned in the text, should include the source image. The indications of the image: type and number of image, image title and source are written in 10 font size. In the text set as image maps, figures, graphs and charts-with the intention of not losing the formatting by the author.

\section{Equations and Formulae:}

When using equations or formulas should be used in Microsoft Word equation editor and numbered.

\section{Paper sending}

Entries must be sent to the email address: lgtz@uacj.mx. With Dr. Luis Enrique Gutiérrez Casas, editor of this publication.

Acceptance of each collaboration will depend on the evaluation of two examiners skilled in the art to be kept anonymous, like the author(s) for the same purposes. 


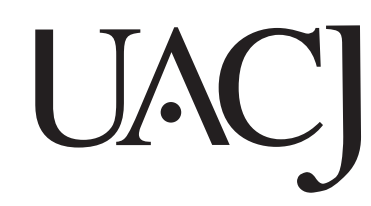

Esta obra se terminó de imprimir en agosto de 2016 Cd. Juárez, Chihuahua, México.

Tiraje: 120 ejemplares 
